This item was submitted to Loughborough's Research Repository by the author.

Items in Figshare are protected by copyright, with all rights reserved, unless otherwise indicated.

\title{
Polydimethylsiloxane and poly(ether) ether ketone functionally graded composites for biomedical applications
}

PLEASE CITE THE PUBLISHED VERSION

https://doi.org/10.1016/j.jmbbm.2019.02.012

\section{PUBLISHER}

(C) Elsevier

\section{VERSION}

AM (Accepted Manuscript)

\section{PUBLISHER STATEMENT}

This paper was accepted for publication in the journal Journal of the Mechanical Behavior of Biomedical Materials and the definitive published version is available at https://doi.org/10.1016/j.jmbbm.2019.02.012

\section{LICENCE}

CC BY-NC-ND 4.0

\section{REPOSITORY RECORD}

Smith, James A., Elisa Mele, Rowan Rimington, Andrew Capel, Mark Lewis, Vadim Silberschmidt, and Simin Li. 2019. "Polydimethylsiloxane and Poly(ether) Ether Ketone Functionally Graded Composites for Biomedical Applications”. figshare. https://hdl.handle.net/2134/37094. 
Polydimethylsiloxane and poly(ether) ether ketone functionally graded composites for biomedical applications

James A. Smith ${ }^{1}$, Elisa Mele ${ }^{2 *}$, Rowan P. Rimington ${ }^{3}$, Andrew J. Capel ${ }^{3}$, Mark P. Lewis ${ }^{3}$, Vadim V. Silberschmidt ${ }^{1}, \operatorname{Simin} \mathrm{Li}^{1}$

${ }^{1}$ Wolfson School of Mechanical, Electrical and Manufacturing Engineering, Loughborough University, Loughborough, Leicestershire, LE11 3TU, UK

${ }^{2}$ Department of Materials, Loughborough University, Loughborough, Leicestershire, LE11 3TU, UK

${ }^{3}$ School of Sport, Exercise and Health Sciences, Loughborough University, Loughborough, Leicestershire, LE11 3TU, UK

*E-mail address: e.mele2@lboro.ac.uk

\section{Abstract}

Functionally graded materials (FGMs), with varying spatial, chemical and mechanical gradients (continuous or stepwise), have the potential to mimic heterogenous properties found across biological tissues. They can prevent stress concentrations and retain healthy cellular functions. $\underline{\text { Here, we show for }}$ the first time the fabrication of polydimethylsiloxane and poly(ether) ether ketone (PDMS-PEEK) composites. These were successfully manufactured as a bulk material and functionally graded (stepwise) without the use of hazardous solvents or the need of additives. Chemical, irreversible adhesion between layers (for the FGMs) was achieved without the formation of hard, boundary interfaces. The mechanical properties of PDMS-PEEK FGMs are proven to be further tailorable across the entirety of the build volume, mimicking the transition from soft to harder tissues. The introduction of 20 wt.\% PEEK particles into the PDMS matrix resulted in significant rises in the elastic modulus under tensile and compressive loading. Biological and thermal screenings suggested that these composites cause no adverse effects to human fibroblast cell lines and can retain physical state and mass at body temperature, which could make the composites suitable for a range of biomedical applications such as maxillofacial prosthetics, artificial blood vessels and articular cartilage replacement. 


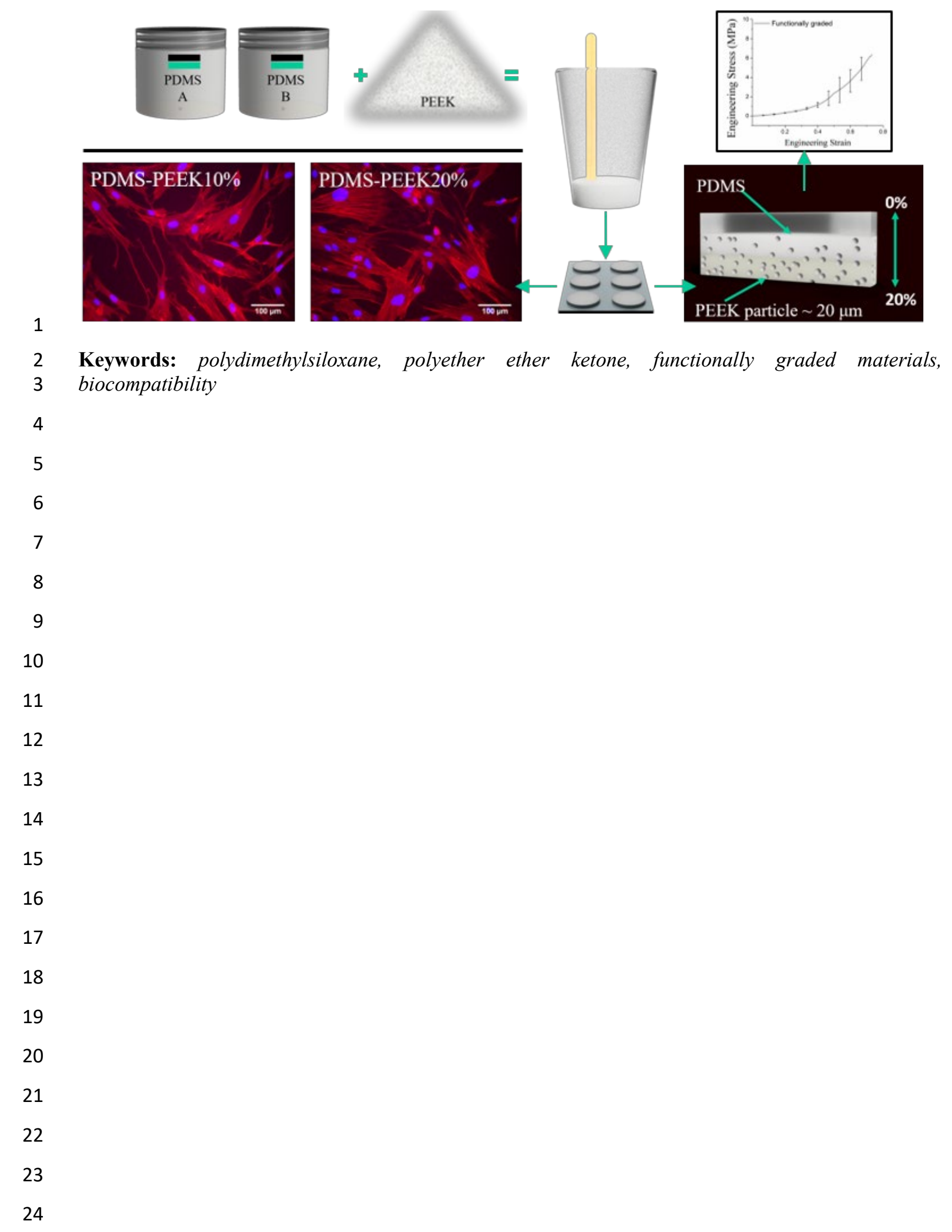




\section{Introduction}

2 Medical devices, implants and artificial tissues have revolutionised patient healthcare over the past century [1,2]. Fundamentally, their success is reliant upon the combination of patient need, sophisticated design, medical staff preference and structural biomaterials [2]. Biomaterials can be defined as any natural or synthetically engineered substance that can replace or prolong body function beyond its natural capacity [3-6]. Synthetic polymeric biomaterials are used extensively throughout the biomedical industry thanks to a multitude of desirable properties, such as ease of surface modification and device manufacture, biocompatibility, controlled mechanical properties, corrosion resistance, and successful operation at body temperature [5,7-9] . However, trends of disease prevalence and ageing populations are placing huge expectation and demand upon such materials and healthcare providers [10]. Hence, there is need to produce economically enhanced polymeric biomaterials that that closely emulate the mechanical properties of the human body.

Blending of immiscible polymers offers a potential solution to this need [11]. Blending processes are relatively cheap and scalable, and bulk material properties can be fine-tuned for application, by controlling fractional volumes introduced [7]. Most polymer composites, however, require the use of additives or toxic solvents to achieve/enhance miscibility and homogeneity throughout the material with separated phase domains [12]. Such material interfaces act as stress concentrators, leading to a loss in mechanical properties and functionality through delamination [13]. For example, blends of ultra-high molecular weight polyethylene (UHMWPE) and polydimethylsiloxane (PDMS) have been proposed to form transitional implants between articulating and impact absorbing components within acetabular cups [14]. The polymers were mixed under high shear and elevated temperature $\left(180^{\circ} \mathrm{C}\right)$ and a decrease in the elastic modulus was observed by increasing the amount of PDMS within the UHMWPE matrix. Another study reports on blends of polycaprolactone (PCL) and poly(L-lactide-co- $\varepsilon$-caprolactone) (PLC) for the treatment of Patent Ductus Arteriosus (PDA, a common form of congenital heart disease) [15]. PCL/PLC/BaSO ${ }_{4}$ solutions ( $\mathrm{BaSO}_{4}{ }_{4}$ was added for X-ray fluoroscopy) in dichloromethane were prepared and then cast on glass substrates to obtain films. Residual solvent (which is toxic) was removed by drying the films under vacuum at $37^{\circ} \mathrm{C}$ for 7 days. The addition of PLC reduced the elastic modulus of the blends from $175 \mathrm{MPa}$ (for PCL/BaSO 4 ) to $110 \mathrm{MPa}$ (for blends containing $50 \%$ of PLC). PCL 
1 was blended also with polylactic acid (PLA) in order to form peripheral nerve conduits [16].

2 Dichloromethane was used to prepare PCL/PLA solutions that were casted to obtain porous films. A

3

4

5

6

7

8

9

washing procedure in $\mathrm{NaOH}$ was used in this case to remove solvent residues.

Polymer composites can be processed to form functionally graded materials (FGMs) that match the anisotropic mechanical behaviour observed in natural biological tissues $[17,18]$. FGMs have generated significant interest within the biomedical research community, leading to the fabrication of numerous, multi-material and multi-structural implants and tissue scaffolds [17,19-22]. Such devices are essential for the promotion of normal cellular functions (adhesion, growth, proliferation and differentiation), especially if multiple cell types exist within layers [22-26].

This study presents both the development and the stepwise-functional grading of biomedically relevant composites comprised of PDMS and PEEK. Unlike other polymer-blended FGMs for biomedical applications, which typically adopt biodegradable thermoplastics with varying spatial arrangements to alter mechanical performances of scaffolds, the work undertaken utilises a thermoset matrix (PDMS) [27-30]. This promoted the chemical adhesion between complete-graded layers to form a dense structure. The combination of PDMS and PEEK was motivated by their contrasting mechanical properties, which could help to bridge the gap between soft (skin, muscle and cartilage) and connective tissue interfaces. PDMS is a flexible thermoset elastomer with a reported elastic modulus between 0.53.0 MPa, rendering it well suited to soft-tissue applications (plastic reconstruction surgery, mammary implants, joint replacement) and medical devices (balloon catheters, artificial heart valves, microfluidic chips) [31-35]. On the contrary, PEEK is a high-performing thermoplastic (elastic modulus of 3-4 GPa), employed within the fields of both trauma care and orthopaedics in the forms of maxillofacial implants, articulation devices, fixation plates and screws, spinal fusion cages, wound dressings, heart valves and pumps, thanks to its good load bearing capacity, chemical resistance and suitability to aggressive sterilization techniques [36-42]. In the literature, the chemical synthesis of PDMS-PEEK copolymer was attempted via the condensation of dimethylamino terminated PDMS and hydroxy terminated PEEK oligomers [43]. The copolymer was intended to be used as impact modifier for the toughening of PEEK. However, its thermo-oxidative instability prevented its application. Here, for the first time, it is shown that PDMS-PEEK can be physically blended without the use of solvents or additives and the resulting 
1 composites can be processed via moulding. In this study, fabrication, material characterisation and

2 mechanical performance are highlighted, as well as cytotoxicity screening of the PDMS-PEEK composites.

\section{Materials and Methods}

\section{Fabrication of PDMS-PEEK composites}

Polydimethylsiloxane $\left(\mathrm{M}_{\mathrm{w}} \sim 60000 \mathrm{~g} / \mathrm{mol}\right.$, Dow Corning ${ }^{\circledR}$ EI-1184 Optical Encapsulant Kit) was purchased from Ellsworth Adhesives Ltd. Poly(ether) ether ketone powder $\underline{\mathrm{M}}_{\mathrm{W}} \sim 78000 \mathrm{~g} / \mathrm{mol}$, VESTAKEEP® 2000 UFP 20) was purchased from Evonik Industries GmbH (Marl, Germany). All chemicals were used without further purification.

PDMS prepolymer solutions were prepared by combining part A prepolymer (dimethyl siloxane, dimethylvinylsiloxy-terminated, dimethylvinylated and trimethylated silica) and part B curing agent (dimethylhydrogensiloxy + catalyst) at a 1:1 ratio. Typically, the catalyst is metal-centred (platinum), $\underline{\text { which promotes hydrosilyation reactions between terminal vinyl groups found in siloxane (part A) and }}$ methylhydrogen siloxane units (part B) [44]. PEEK particles were then introduced into the PDMS solution at 10 (PDMS-PEEK10\%) and 20 wt.\% (PDMS-PEEK20\%). Blends with $30 \mathrm{wt} . \%$ and $40 \mathrm{wt} . \%$

PEEK particles were also investigated; however, inconsistencies in manufacture were experienced (see supporting information Fig. S1). Each fractional mixture was manually stirred to obtain a uniform dispersion of the PEEK powder. This was identified at the point at which the PEEK powder was unable to be visually separated from the bulk PDMS, forming an opaque, tan-coloured-gel like substance, which increased in viscosity, upon rising PEEK fractional volumes.

The PDMS-PEEK dispersions were placed into a desiccator for $\sim 20$ minutes, removing air introduced by mixing. A compressed air gun was used to break the surface tension of any remaining bubbles in the specimens. The PDMS-PEEK mixtures were poured into machined aluminium moulds following ASTM D638-14 (type iv); (gauge length $25.0 \mathrm{~mm}$; width $6.0 \mathrm{~mm}$; thickness $3.2 \mathrm{~mm}$ ), ASTM D395-16 (type $\left.1^{\mathrm{A}}\right)$ compressive set, $(\varnothing 29.5 \mathrm{~mm}$; thickness $12.5 \mathrm{~mm})$ standards and left to cure at $70{ }^{\circ} \mathrm{C}$ for 1 
1 hour. Samples were immediately removed from the oven and left to cool at room temperature, prior to

2 testing.

3 To produce functionally graded specimens, PDMS-PEEK blends of equal volume were built up in a

4

5

6

7 controlled layer-by-layer process. In this case, PDMS-PEEK20\% blends were cast first into aluminium moulds similar to ASTM D395-16 (type $1^{\mathrm{A}}$ ) compressive set, (Ø $29.5 \mathrm{~mm}$; thickness $12.5 \mathrm{~mm}$ ) and left to cure at room temperature for 24 hours. This process was repeated for subsequent PDMS-PEEK10\% and PDMS layers. The semi-cured FG specimens were then held at $70^{\circ} \mathrm{C}$ for 1 hour to ensure full cure, before being removed from oven and cooled at room temperature. Dimensional accuracy of the attained specimens was assessed with Vernier calliper (Digital 150mm, Duratool).

\section{Morphology and surface characterisation}

PEEK particle size was examined with Mastersizer 3000 (Malvern) laser-diffraction particle-size analyser. Both surface and cross-sectional morphologies of the PDMS-PEEK composites were analysed with scanning electron microscopy (TM3030, Hitachi). A $15 \mathrm{~nm}$ coating of Au-Pd (80:20 ratio) was deposited onto the samples by sputter coater (Q150T ES, Quorum) prior to SEM inspection.

\section{Chemical and thermal analysis}

Energy dispersive X-ray (EDX) analysis of the composites was undertaken to examine their elemental composition (TM3030, Hitachi). Five distinct points were assessed across five individual specimens for each composite. Thermal behaviour of the PDMS-PEEK composites was determined by thermogravimetric analysis (TGA) and differential scanning calorimetry (DSC). Samples with a weight of $10 \mathrm{mg}$ were loaded into designated aluminium pans and exposed to temperatures ranging from 0-400 ${ }^{\circ} \mathrm{C}$ for TGA (Q5000IR, TA Instruments) and from $20-600{ }^{\circ} \mathrm{C}$ for DSC (2920, TA Instruments) at a scan rate of $10^{\circ} \mathrm{C} / \mathrm{min}$ in a nitrogen atmosphere.

\section{Mechanical performance}

Both uniaxial tensile and compressive tests were performed to characterise the mechanical properties of the PDMS-PEEK blends, using Instron universal testing systems (Instron 3344 and 3363), equipped with $1 \mathrm{kN}$ and $10 \mathrm{kN}$ load cells, respectively. Prior to the tests, a $5 \mathrm{~N}$ preload was applied to overcome flexible nature of the tensile specimens, while polytetrafluorethylene (PTFE, WD-40) lubricant was applied to the surfaces between compression plates and specimens to reduce any 'barrelling' effect 
caused by surface friction. A quasi-static strain rate of $0.001 \mathrm{~s}^{-1}$ was applied in both tensile and compressive tests. Specimen failure was identified as a drop-in load of $5 \%$. Five tensile and five compressive pieces were tested for each PDMS-PEEK blend.

\section{Cytotoxicity screening}

\subsubsection{Cell culture}

Human dermal fibroblasts (HDF), all below passage 13 (ATCC), were cultured in T80 flasks (Nunc ${ }^{\mathrm{TM}}$, Fisher Scientific, UK) and incubated at $5 \% \mathrm{CO}_{2}$ atmosphere and $37{ }^{\circ} \mathrm{C}$ (HERA cell 240i, Fisher Scientific, UK) in growth medium (GM), composed of $89 \%$ Dulbecco modified Eagle's medium (DMEM, Sigma Aldrich, UK), 10\% foetal bovine serum (FBS, Pan Biotech, UK) and 1\% penicillinstreptomycin (P/S, Fisher Scientific, UK) until 80\% confluence was obtained. Incubated cells GM was changed every $24 \mathrm{~h}$ prior to being harvested for experimental use.

\subsubsection{Polymer sample preparation}

All samples were sterilized with ultra-violet (UV) light for $\geq 1 \mathrm{~h}$, prior to being adhered to culture well plates using an in-house bio-adhesive (aquarium glue) that was found to be biocompatible [45]. Samples were then rinsed with $70 \%$ industrial methylated spirit (IMS) solution and left to air-dry prior to being washed with phosphate buffered saline (PBS) solution. Each polymer disc (Ø $30 \mathrm{~mm}$; thickness $1 \mathrm{~mm}$; approx. surface area $15 \mathrm{~cm}^{2}$ ) provided a surface-area-to-volume ratio of $3 \mathrm{~cm}^{2} \mathrm{~mL}$ and was designed to cover most of the culture area of a six-well plate. Where possible, the methodology was devised with the international standards organisation (ISO 10993) guidelines as previously reported [46].

\subsubsection{Experimental treatment}

When determining the biocompatibility of biomedical materials, interactions between the chemical leachate of such materials and cell cultures must be assessed. Hence, sample discs were used to evaluate the indirect $(n=1)$ biocompatibility of each polymer per repeat $(n=3)$. Experiments generated $n=3$ per condition, totalling $n=6$ per analysis at each specific time-point, derived from $n=3$ experimental repeats. HDF cells were seeded at a density of $10^{4}$ cells per $\mathrm{cm}^{2}$ on tissue culture plastic within chemically leached medium of each polymer. To obtain this, polymer blend discs were attached to culture wells that remained acellular (containing only medium (denoted "MEDIA ONLY"). Chemically leached medium from each polymer was then transferred to its corresponding experimental well, 
ensuring that cellular medium was directly representative of cumulative polymer degradation at each specific time-point. Each MEDIA ONLY well was preincubated with $2 \mathrm{~mL}$ GM for $24 \mathrm{~h}$ prior to commencing each experiment, to ensure cells were seeded within medium that had been exposed to the chemical leachate of each polymer. Once transferred to experimental wells, acellular wells were replenished with $2 \mathrm{~mL}$ GM before each subsequent media change. HDF cell viability was determined at $24 \mathrm{~h}$ intervals $(24,48$ and $72 \mathrm{~h}$ ), prior to being fixed for morphological analyses at experimental termination time-points $(72 \mathrm{~h})$.

\subsubsection{Cell viability alamarBlue ${ }^{\circledR}$}

To determine proliferation/viability of HDFs when interacting with polymer composites, alamarBlue ${ }^{\circledR}$ reagent (diluted 1:10 in DMEM containing 1\% P/S) was added at 24, 48 and $72 \mathrm{~h}$ time-points. Cells were washed twice with $2 \mathrm{~mL}$ PBS before being treated with $2 \mathrm{~mL}$ per well alamarBlue ${ }^{\circledR}$ stock solution and humidified at $5 \% \mathrm{CO}_{2}$ and $37^{\circ} \mathrm{C}$ for $4 \mathrm{~h} .100 \mu \mathrm{L}$ of solution, per well, was then added to a 96-black well plate and analysed for fluorescence intensity. Increased fluorescence of alamarBlue ${ }^{\circledR}$ reagent is indicative of an increase in cellular viability. alamarBlue ${ }^{\circledR}$ fluorescence signal was excited at 540-570 $\mathrm{nm}$ (peak excitation: $570 \mathrm{~nm}$ ) and emitted at 580-610 nm (peak emission: $585 \mathrm{~nm}$ ).

\subsubsection{Immunofluorescence and morphological analyses}

At experimental termination time-point $(72 \mathrm{~h}$ ), cells were washed twice in $2 \mathrm{~mL}$ PBS per well prior to being fixed in $3.7 \%$ paraformaldehyde solution. Once fixed, HDF cell cultures were permeabilised (Triton X-100, Fisher, 1:500) and labelled for cytoskeletal protein F-actin and nuclear DNA using molecular probe rhodamine phalloidin (1:200; Life Technologies, Molecular Probes) and 4',6diamidino-2-phenylindole (DAPI, 1:2000) for $\geq 1 \mathrm{~h}$. Fluorescence images were captured using a Leica DM2500 fluorescence microscope (20×) with manufacturer's software (Leica Application Suite X), and analysed using IMAGE J 1.50a/Fiji (Java 1.6.0_24) software (National institute of Health, Bethesda, MD). Image inclusion criteria were set at $\geq 5$ images per well. Nuclei number analysis was performed using an in-house macroinstruction designed for Fiji image analysis software.

\section{Statistical analysis}

Both mechanical and cell-viability data sets were statistically analysed with software package (SPSS 24, IBM). 1 x 3 one-way analysis of variance (ANOVA) was undertaken to assess mechanical data that 
met parametric assumptions. Where significant observations were met, Tukey post-hoc analysis was used to determine differences between sample groups. Where parametric assumptions were violated, non-parametric Welch's ANOVA, followed by Games-Howell post-hoc analysis, was used to determine statistical differences between sample groups. A 6 × 3 ANOVA was undertaken to analyse cell viability. One-way ANOVA ( 1 x 6) was used to analyse the morphological nuclei number concerned with experimental termination time-points. Here, where significant interactions were observed, Bonferroni post-hoc analysis was used to assess differences between conditions at specific time-points. Non-parametric Kruskal-Wallis $(H)$ analysis was undertaken where data violated parametric assumptions. Mann-Whitney $(U)$ tests were then utilised to determine significance between conditions, in accordance with Bonferroni correction to account for incremental type- 1 error. All data are reported as mean \pm standard deviation (SD). Significance was assumed at $p<0.05$.

\section{Results and Discussion}

\subsection{Morphology and surface characterisation}

The replica moulding technique was used to fabricate PDMS samples with and without PEEK particles for ease of processing and dimensional accuracy [47]. PDMS samples were optically transparent and completely void of defects despite thicknesses up to $12.5 \mathrm{~mm}$ (Fig. 1a). Upon the introduction of PEEK particles, the elastomer became both opaque and tan coloured. Polymer blends became duller and washed out in appearance as PEEK fractional volumes increased (Figs. 1b-c and S1a). The PEEK particles were irregular in morphology, with an average size distribution of 10-50 $\mu \mathrm{m}$ (Fig. 1d). During sample preparation, it was observed that organic solvents were not required to obtain homogenous dispersions of PEEK particles throughout the liquid PDMS prepolymer (an advantage over previous works) $[48,49]$. This was credited to the low surface tension of the PDMS prepolymer $\left(\sim 20 \mathrm{~mJ} / \mathrm{m}^{2}\right)$ that promoted the wetting of PEEK particles (surface energy $\sim 50 \mathrm{~mJ} / \mathrm{m}^{2}$ ) and limited the formation of aggregates [50-52]. The presence of PEEK within the PDMS elastomer had no detrimental effects upon the curing process, which was achieved after 1 hour at $70{ }^{\circ} \mathrm{C}$, as for pristine PDMS. Often, solvents are an essential commodity to ensure successful multi-material processing [53]. However, their use in 
1 manufacturing can add significant cost (purchase, recycling and safe disposal) and be detrimental to

2 both animal models and the environment [54]. Hence, the materials here developed were completely

3 solvent-free to ensure biocompatibility and alleviate cytotoxicity [53]. SEM analysis of the obtained

4 composites (surfacing facing the mould, bottom) revealed a smooth surface finish for the PDMS control

5 sample (Fig. 1e) and enhanced surface roughness for PDMS-PEEK10\% (Fig. 1f) and PDMS-PEEK20\%

6 (Fig. 1g). The increase in surface roughness is attributed to semi-embedded PEEK particles, forming

7 protrusions and craters (blue arrows in Figs. 1f and $1 \mathrm{~g}$ ) across the composite surfaces. PEEK particles

8 were uniformly distributed throughout the sample and, as expected, their density increased with

9 fractional PEEK volume. Observations drawn from sample cross sections also indicated significant PEEK homogeneity throughout the PDMS matrix for PDMS-PEEK10\% and PDMS-PEEK20\% (Fig.

11 1h-1j). During the cross-linking process, the PEEK particles remained homogenously distributed within the PDMS matrix without precipitation or aggregation at the bottom of the mould, prompting desirable manufacturability and consistency.

14 Cavities (red dashed boxes in Figs. 1i and 1j) existing within the cross-sectional area of the PDMSPEEK10\% and PDMS-PEEK20\% are attributed to directional shear forces applied by a scalpel blade during samples preparation for SEM imaging. The cutting force caused the delamination of loosely bound PEEK particles from their PDMS matrix. This demonstrates that the liquid PDMS prepolymer coated the surface of each single PEEK particle (during PDMS and PEEK mixing) and broke down aggregates in the PEEK powder without need of solvents or high shear mixing procedures. 

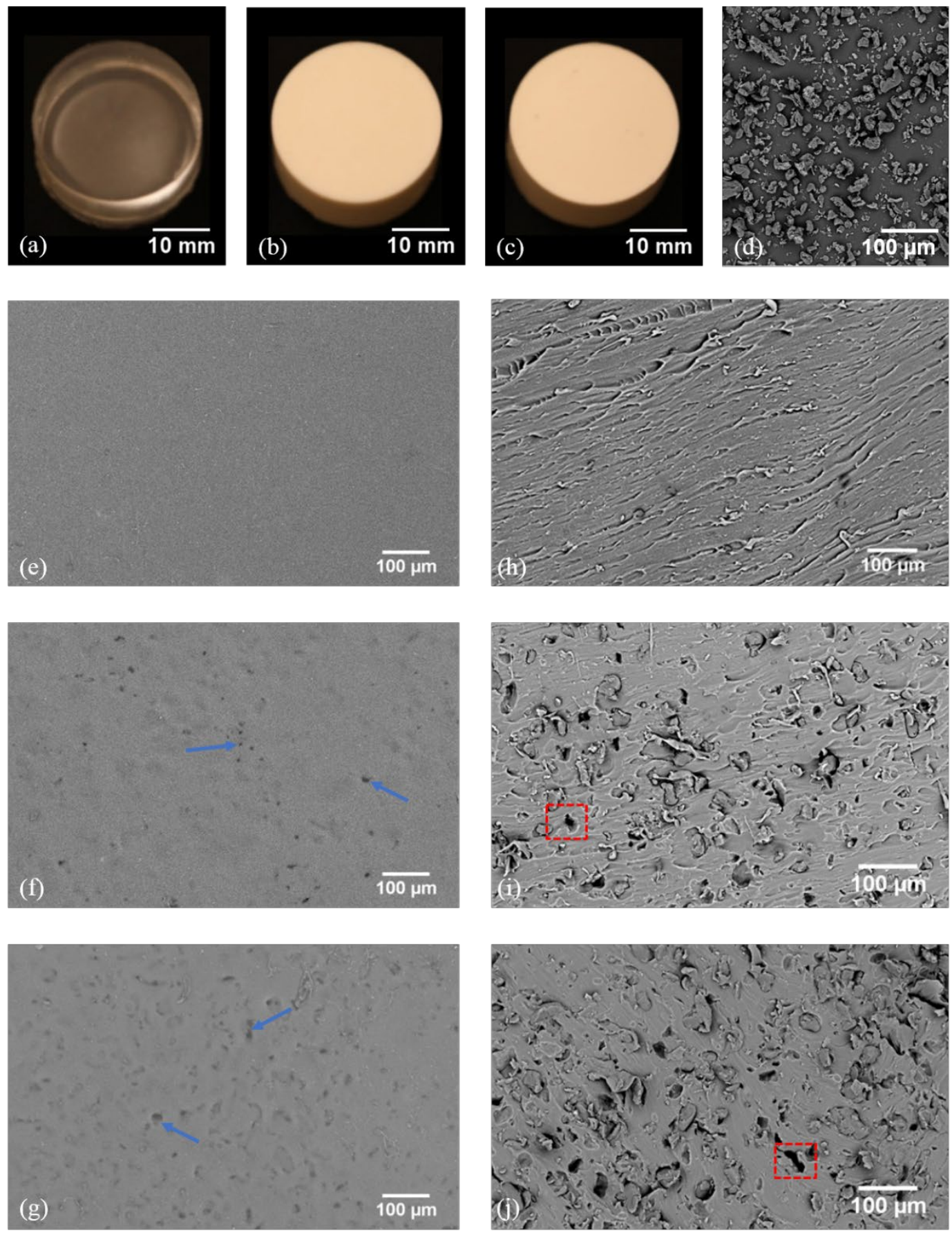

Fig. 1. Photographs of bulk specimens; PDMS (a), PDMS-PEEK10\% (b), and PDMS-PEEK20\% (c). Surface morphology (SEM) of PEEK particles (d), PDMS (e), PDMS-PEEK10\% (f) and PDMSPEEK $20 \%$ (g). Cross sectional morphology (SEM) of PDMS (h), PDMS-PEEK10\% (i) and PDMSPEEK20\% (j). Arrows (blue) indicate surface protrusions and craters on composite surface. Cavities (red dashed boxes) formed during sample preparation for imaging. 


\subsection{Chemical and thermal analysis}

EDX analysis was performed across the surface of PDMS, PDMS-PEEK $10 \%$ and PDMS-PEEK20\% as well as a PEEK reference, to determine elemental composition, and, in turn, ensure both the validity of supplied materials and batch quality of the specimens (Fig. S2). Both silicon and oxygen are fundamental constituents of PDMS and, hence, found in abundance in the PDMS control and the PDMS-PEEK blends. As expected, silicon slightly declined as fractional volumes of PEEK increased, indicating that PEEK particles were partially exposed at the surface. The minimal rise in oxygen was attributed to the introduction of the PEEK, which was found bound to carbon throughout its structure.

A gradual rise in carbon was witnessed with increasing fractions of PEEK, as it is the primary constituent of PEEK's chemical skeleton.

The thermal properties of the PDMS-PEEK composites were investigated because thermal stability and mass retention at body $\left(37^{\circ} \mathrm{C}\right)$ and sterilisation temperatures $\left(121^{\circ} \mathrm{C}\right)$ are prerequisites for the fabrication of structural implants and functional biomedical devices [55]. TGA showed that the PDMS and PDMSPEEK composites were stable across a broad range of temperatures (Fig. 2a and S3a). Between 37$200^{\circ} \mathrm{C}$, negligible mass loss was experienced by all polymer samples. As temperatures approached $300^{\circ} \mathrm{C}$, the masses retained for PDMS, PDMS-PEEK $10 \%$, PDMS-PEEK $20 \%$ and PEEK were all higher than $98.5 \%$. The mass retained for PEEK stayed consistent (99\%) as temperatures rose to $500^{\circ} \mathrm{C}$, while significant mass reduction was observed for PDMS (-21\%), PDMS-PEEK10\% (-17\%) and PDMSPEEK20\% (-13\%) compared to mass at room temperature, which is inversely correlated to PEEK fractional volume. The corresponding mass losses observed between $400-500{ }^{\circ} \mathrm{C}$ are indicative of the thermal 'unzip-degradation' depolymerization of PDMS, resulting in the cleavage of Si-O-Si bonds and the subsequent formation of cyclic siloxanes of varying chain lengths [56,57]. The increased retention of mass observed for PDMS-PEEK10\% and PDMS-PEEK20\% against the PDMS control is attributed $\underline{\text { to the higher specific heat capacity of the PEEK fraction. As PEEK inclusions increased and the distance }}$ between adjacent particles declined, higher thermal tolerances were achieved throughout the matrix. Due to the chemical stability of PEEKs aromatic backbone, degradation of the polymer was not witnessed between $400-500^{\circ} \mathrm{C}[58-60]$. At $600^{\circ} \mathrm{C}$, mass retention for all samples demonstrated a sharp drop, with PDMS, PDMS-PEEK10\%, PDMS-PEEK20\% and PEEK retaining final masses of 46\%, 
$142 \%, 62 \%$ and $65 \%$, respectively. Of all the polymers, PEEK was most thermally stable (degradation

2 temperature $\sim 550^{\circ} \mathrm{C}$ ), consistent with the existing literature $[60,61]$. As temperatures surpassed $500^{\circ} \mathrm{C}$,

3 PDMS and its composites experienced further mass loss due to thermal 'rearrangement-degradation,'

4 promoting, in turn, the rearrangement of $\mathrm{Si}-\mathrm{O}-\mathrm{Si}$ bonds and the heterolytic cleavage of $\mathrm{Si}_{-} \mathrm{CH}_{3}$ bonds,

5 to form methane and additional cyclic oligomers $[62,63]$. Between $500-600^{\circ} \mathrm{C}$, thermal degradation of

6 PEEK was initiated, with the associated mass loss attributed to the random cleavage of ether and ketone groups linking the aromatic rings together [60]. It was reported that beyond $650^{\circ} \mathrm{C}$ carbonyl groups are

8 cleaved, forming radical decomposition intermediates such as phenols, dibenzofuran, $\mathrm{CO}, \mathrm{CO} 2$ and

9 carbonaceous char $[60,64,65]$.

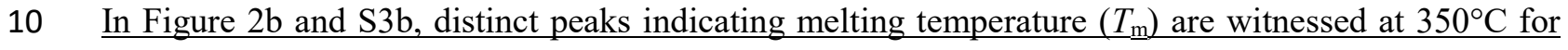

11 PDMS-PEEK10\%, PDMS-PEEK20\% and PEEK. A $T_{\mathrm{m}}$ peak for PDMS is not observed due to its step

12 change occurring at a reported $-40^{\circ} \mathrm{C}[66]$. A step change, indicative of glass transition temperature

$13\left(T_{\mathrm{g}}\right)$, was observed at $140^{\circ} \mathrm{C}$ in PEEK (Fig. 2b), consistent with previous findings; however, this became

14 less prominent (reduction in area under the curve) as fractional volume of PEEK declined to $20 \mathrm{wt} . \%$

$15[67,68]$. PDMS's $T_{\mathrm{g}}$ was previously reported between -115 to $-125^{\circ} \mathrm{C}[66,69,70]$. The obtained TGA

16 and DSC data suggest that the PDMS-PEEK composites have the capacity to retain mass and phase

17 well beyond body and sterilisations temperatures and, hence, are suitable for biomedical applications. 

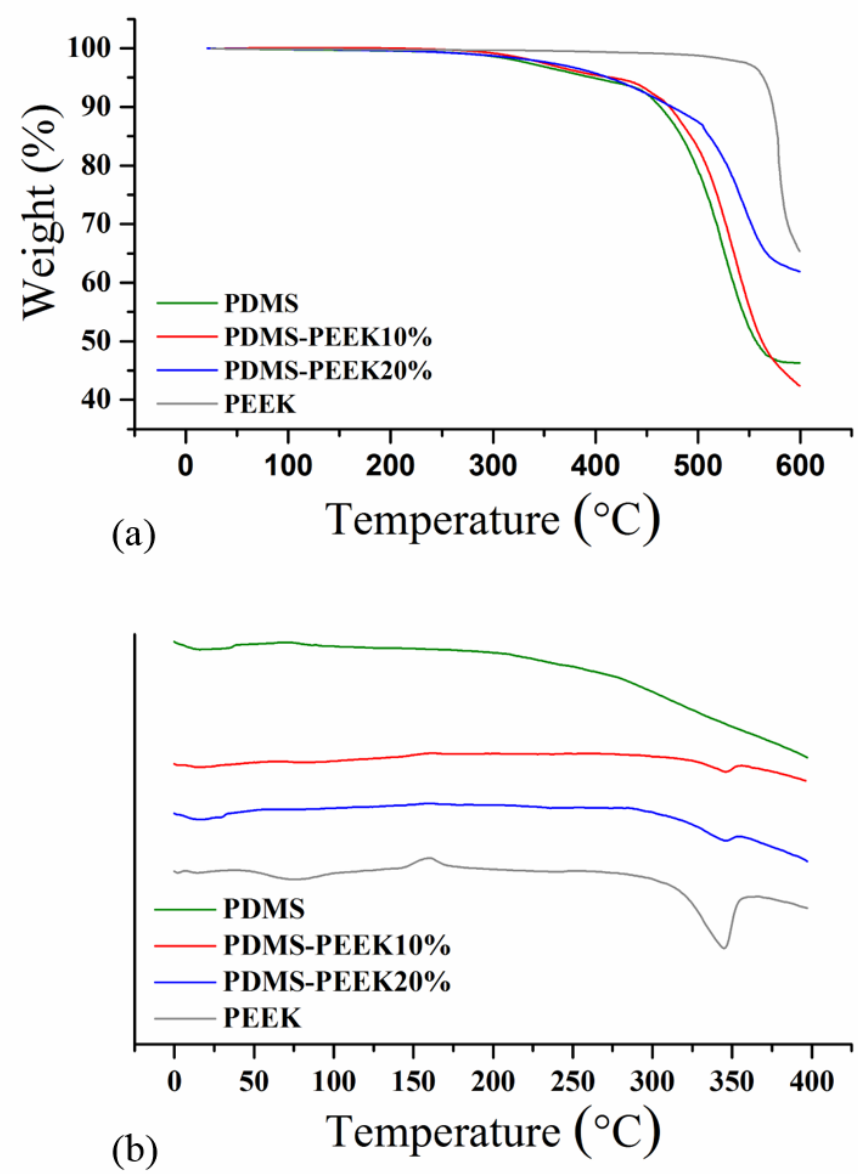

Fig. 2. TGA (a) and DSC (b) of PDMS, PDMS-PEEK10\%, PDMS-PEEK20\% and PEEK samples.

1

\section{$2 \quad 3.3$ Mechanical performance}

3 The mechanical properties of the PDMS-PEEK composites were evaluated in both tension and

4 compression (Fig. 3). All samples exhibited stress-strain behaviour that are typical of PDMS-based

5 materials, i.e. a period of linearity, followed by non-linearity and then subsequent ultimate failure (Fig.

6 3a) [71-73]. The modulus of toughness $U_{t}$ (calculated as the area under the graph) for both tensile and

7 compressive specimens was recorded. PDMS exhibited a $U_{\mathrm{t}}$ of $0.7 \pm 0.2 \mathrm{MPa}$ (tension) and $2.1 \pm 0.4 \mathrm{MPa}$

8 (compression). The addition of PEEK fractional volumes saw a rise in toughness across all the PDMS-

9 PEEK composites. In tension the inclusion of $10 \mathrm{wt} \%$ and $20 \mathrm{wt} \%$ PEEK determines a 1.1-fold increase over the control $(0.8 \pm 0.1 \mathrm{MPa}$ for PDMS-PEEK10\% and $0.7 \pm 0.2 \mathrm{MPa}$ for PDMS-PEEK20\%).

11 Compared to PDMS, PDMS-PEEK10\% and PDMS-PEEK20\% saw 1.6-fold (3.3 $\pm 0.4 \mathrm{MPa})$ and 2.1-

12 fold (4.4 $\pm 0.2 \mathrm{MPa})$ increases, respectively. 
1 In tension (Fig. 3b, top quadrant), the elastic modulus (calculated for a strain interval between 10-20\%

2 in the linear region of the curve) obtained for the PDMS control sample was $0.95 \pm 0.03 \mathrm{MPa}$, in

3 agreement with previous studies on PDMS-based materials [35,72,74]. The addition of PEEK

4 determined statistical rises $(p<0.05)$ in the elastic modulus for both PDMS-PEEK $10 \%(1.40 \pm 0.15 \mathrm{MPa})$

5 and PDMS-PEEK20\% (3.68 $\pm 0.59 \mathrm{MPa})$, corresponding to a 1.5-fold (PDMS-PEEK10\%) and 3.9-fold

6 increase (PDMS-PEEK20\%) compared to the PDMS control, respectively. Under compressive load

7 (Fig. 3b, bottom quadrant), the elastic moduli recorded for PDMS-PEEK10\% and PDMS-PEEK20\%

8

9

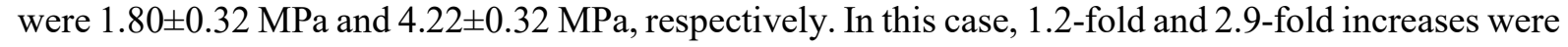
achieved over the PDMS control (1.46 $\pm 0.45 \mathrm{MPa})$ by the incorporation of 10 and 20 wt.\% PEEK into the elastomeric matrix. Statistical significance was observed between PDMS and PDMS- PEEK20\%, and PDMS-PEEK10\% and PDMS-PEEK20\% but not between PDMS and PDMS-PEEK10\%. PDMS specimens (Fig. 3c, top quadrant) exhibited a peak stress of $1.14 \pm 0.35 \mathrm{MPa}$ in tension, whereas values of $1.42 \pm 0.16 \mathrm{MPa}$ (1.2-fold) and $1.57 \pm 0.2 \mathrm{MPa}$ (1.4-fold) were recorded upon the introduction of 10 wt.\% and 20 wt.\% PEEK, respectively, with no statistical significance $(p>0.05)$ observed between groups. In compression (Fig. 3c, bottom quadrant), the peak stresses of all respective groups were significantly different $(p<0.05)$ from each other. Peak stress values were recorded as were $5.53 \pm 0.41$

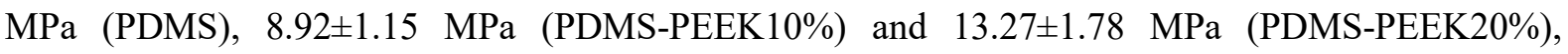
corresponding to 1.6-fold and 2.4-fold increases over PDMS, respectively. 

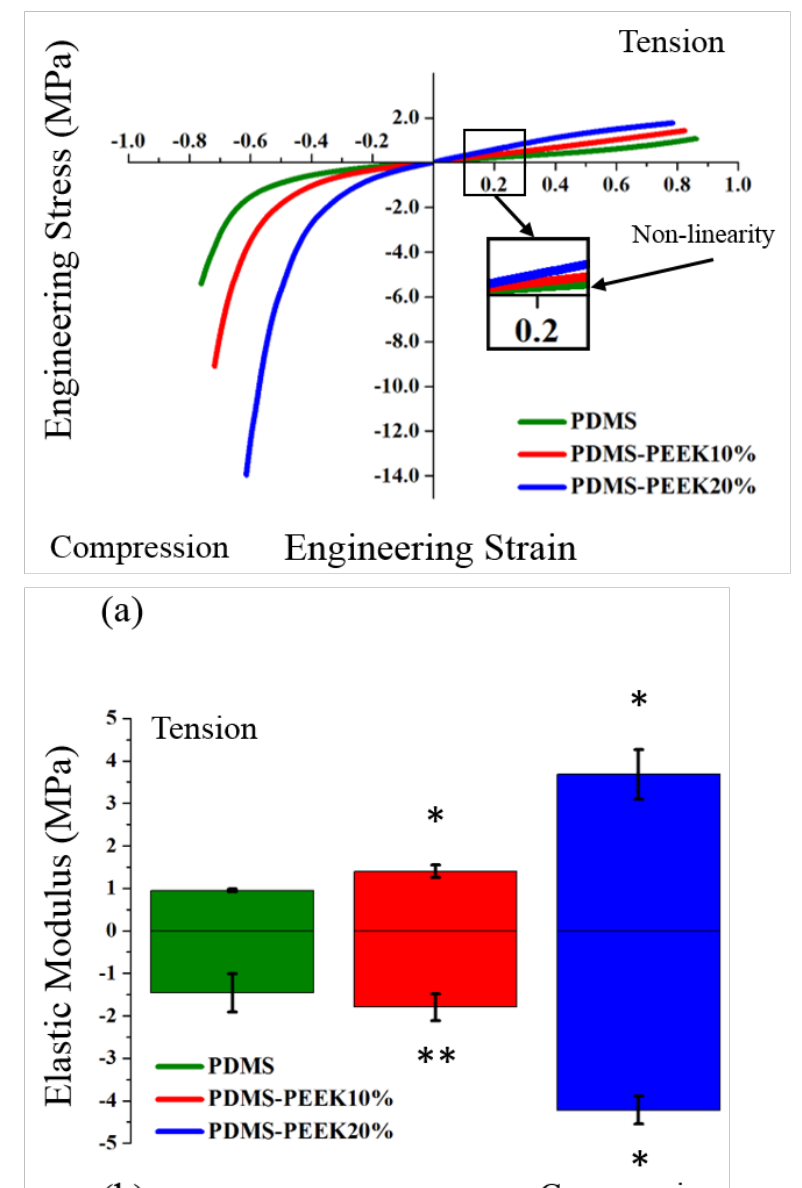

(b)

Compression

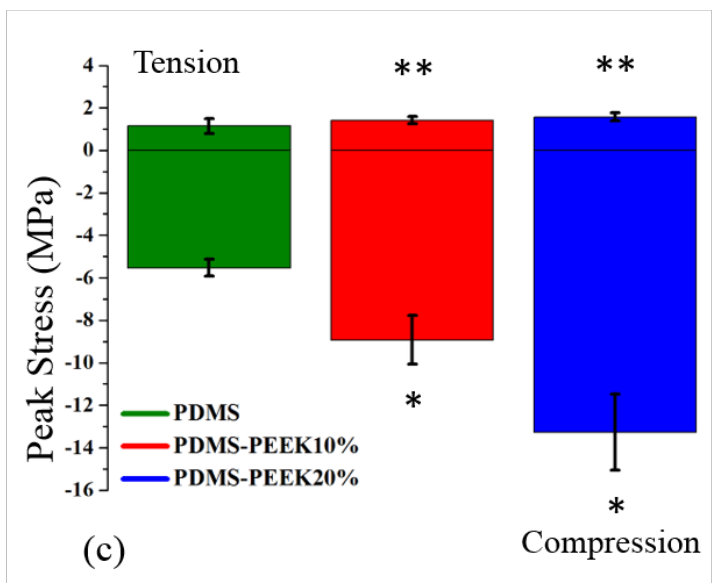

Fig. 3. Engineering stress/strain curve (a), elastic moduli (b) and peak stress (c) for PDMS (green), PDMS-PEEK10\% (red) and PDMS-PEEK20\% (blue). Samples in; tension (top) and compression (bottom). *Statistical significance $(\mathrm{p}<0.05)$ and $* *$ no-statistical significance $(\mathrm{p}>0.05)$ observed compared to PDMS control. 
1 Evidently, the incorporation of PEEK into the PDMS matrix had a significant impact on the mechanical

2 performance of the polymer composite. Typically, the polymers utilised as the matrix are 'state-of the art' with a designated application (PEEK for orthopaedic devices; UHMWPE for articulating femoral heads and PDMS for soft tissues) and the fillers act to enhance or change a specific property (mechanical, thermal, biocompatibility, etc.) [75]. Hence, it seemed appropriate to compare these novel PDMS-PEEK materials to existing biomedical composites, specifically those with a PDMS matrix (Table 1). For PDMS-HA composites, the elastic modulus was reported as $0.7 \pm 0.2 \mathrm{MPa}(10 \mathrm{wt} . \% \mathrm{HA})$ and $0.7 \pm 0.3(20 \mathrm{wt} . \% \mathrm{HA})$, which is a 1.1-fold and 1.2-fold increase over their control [76]. Here, 1.5fold and 3.9-fold increase in the elastic modulus are reported for PDMS-PEEK10\% and PDMSPEEK $20 \%$, respectively, in relation to PDMS. The ultimate tensile strength was $2.0 \pm 0.2 \mathrm{MPa}$ and $\underline{2.2 \pm 0.6 \mathrm{MPa} \text { for PDMS-HA10\% and PDMS-HA20\%, respectively, correlating to 1.0-fold and 2.3-fold }}$ increases over the control [76]. For the PDMS-PEEK blends, 1.4 $\pm 0.2 \mathrm{MPa}$ (PDMS-PEEK10\%) and 1.6 $\pm 0.2 \mathrm{MPa}$ (PDMS-PEEK20\%), which equate to 1.2-fold and 1.4-fold increases over PDMS, were obtained. Increased levels of elongation were also observed for PDMS-HA10\%, PDMS-HA20\%, PDMS-Polytetrafluroethylene (PTFE) $10 \%$ and PDMS-PTFE20\% [77]. This trend was initially witnessed in PDMS-PEEK10\%, however for PDMS-PEEK20\% elongation at break decreased, following the trends of Polyurethane (PU)-UHMWPE [78].

The divergence between tensile and compressive peak stresses among different groups can be attributed to both the intrinsic properties of the composite polymers and differences in deformation mechanism experienced by materials under load. PDMS' structure is comprised of both cross-linked (covalently bonded) polymer chains (forming a 3D network) and loosely bound (Van der Waals') entangled, amorphous chains (Fig. 4a.i) [82]. As tensile load is applied to the elastomers (above their $T_{\mathrm{g}}$ ), the secondary bonds holding the chains together break, enabling them to slide past one another reversibly within the linear region (load carrying capacity matches deformation rate) [82]. In turn, these chains align and re-orientate themselves parallel to the direction of loading (Fig. 4a.ii) [83]. As greater number of polymer chains align and stretch (to absorb energy), irreversible plastic deformation occurs, exhibited by a small but distinctive toe region in the stress-strain curve [84]. In attempt to dissipate stress, the chemical backbone rotates until bond dislocation occurs, creating micro-cavitation, leading to failure 
1 (Fig. 4a.iii) [83-85]. In comparison, compressive PDMS specimens (Fig. 4b.i) experience similar chain

2 sliding as in tension; however, the entangled chains become interpenetrated with one another reducing molecular mobility and increasing polymer stiffness at lower strain magnitude (Fig. 4b.ii) [86]. As the re-orientation and superimposed polymer entanglement is passive (due to lateral contraction), the stressstrain curve exhibited a clear heel region at relative higher strain magnitude. The subsequent increase of the stress-strain curve is result of interlocked polymer deformation, until covalent bond breakage leads to buckling and rupture (Fig. 4b.iii) [87].

By introducing PEEK into the elastomeric matrix, stiffness increased as a function of particle loading (up to $20 \mathrm{wt} . \%$ ). Rationale for this increase in stiffness is attributed to the higher concentration of PEEK particles, restricting chain mobility and the higher intrinsic properties of the particles compared to PDMS [88-90]. Consequently, higher loading was necessary to plastically deform the PDMS-PEEK composites in both tension and compression, correlating with the higher elastic moduli observed. After achieving peak stress, the process of PEEK particle detachment from the PDMS matrix ensued, leading to voids and rupture in tension. Under compressive loading, the distance between bound PEEK particles decreases with load, resulting in material consolidation [89]. After peak stress, the bound elastomer was stripped away from the bound PEEK particles, generating voids that are unable to dissipate the applied stress. Elongation at break recorded for PDMS, PDMS-PEEK10\% and PDMS-PEEK20\% were $189.2 \pm 13.1 \%, 191.7 \pm 6.0 \%$ and $180.7 \pm 15.3 \%$ in tension, respectively (Fig. 4c, top quadrant), and $31.1 \pm 9.5 \%, 25 \pm 3.3 \%$ and $39.0 \pm 2.1 \%$ in compression (Fig. $4 \mathrm{c}$, bottom quadrant), respectively. The results reported for PDMS agreed with previous findings [35,74]. It is understood that the levels of elongation at break can be controlled by the fraction of particle filler as well as curing temperature and level of cross-linker $[71,74,89]$. Recent examples of such behaviour include the addition of starch and cocoa shell to PDMS (for biodegradable packaging) which caused a 10 -fold and 68 -fold reduction in elongation at break $[49,91]$.

Importantly, in this study, the addition of PEEK particles into the PDMS elastomer did not affect sample's elongation at break significantly $(p>0.05)$. The ability of the PDMS-PEEK samples to retain similar levels of ductility, yet increase their load-bearing capacity is considered highly advantageous compared with previous works $[49,91]$. Hence, these polymer composites could be adopted for a far 
1 greater range of soft-tissue engineering applications. One example of note is the field of maxillofacial

2 prosthetics. Unlike commercial elastomers reported in literature, the tensile properties obtained from

3 PDMS-PEEK10\% (1.40 $\pm 0.15 \mathrm{MPa})$ composites are far more representative of submandibular tissue

$4 \quad(1.28 \pm 0.06 \mathrm{MPa})[92,93]$. It is understood that skin possesses age-dependent biomechanical properties,

5 and as such, the PDMS-PEEK composites could be tailored to match the mechanical properties of tissue

6 as a function of time [94]. Further applications could include prosthetic blood vessels (saphenous vein

7 and arterial walls) and articular cartilage, as the elastic moduli for the PDMS-PEEK composites are

8 within the reported range [25].

9

10

11

12

13

14

15

16

17

18

19

20

21

22 
Table 1. Composition and mechanical parameters of biomedical composites with PDMS matrix (RT - room temperature, CS - crosshead speed).

\begin{tabular}{|c|c|c|c|c|c|c|c|}
\hline Composites & $\begin{array}{c}\text { Volume fraction } \\
\text { (wt.\%) }\end{array}$ & $\begin{array}{c}\text { Elastic modulus } \\
(\mathrm{MPa})\end{array}$ & $\begin{array}{l}\text { Ultimate tensile } \\
\text { strength (MPa) }\end{array}$ & $\begin{array}{c}\text { Elongation at } \\
\text { break (\%) }\end{array}$ & Sample preparation & Test parameters & Ref. \\
\hline \multirow{4}{*}{$\begin{array}{l}\text { UHMWPE- } \\
\text { PDMS }\end{array}$} & 0 & 34 & - & - & \multirow{4}{*}{$\begin{array}{l}\text { Shear mixed }(100 \mathrm{rpm} \text { at } \\
\left.180^{\circ} \mathrm{C}\right) \text {, compression } \\
\text { moulding }\left(160^{\circ} \mathrm{C}\right)\end{array}$} & \multirow{4}{*}{$\begin{array}{l}\text { Tensile } \\
\mathrm{CS}=50 \mathrm{~mm} / \mathrm{min}\end{array}$} & \multirow{4}{*}[14]{} \\
\hline & 10 & 32 & - & - & & & \\
\hline & 20 & 26 & - & - & & & \\
\hline & 30 & 11 & - & - & & & \\
\hline \multirow[t]{6}{*}{ PDMS-HA } & 0 & 0.63 & 1.97 & 525 & \multirow{6}{*}{$\begin{array}{l}\text { Two-roll mixer, hot } \\
\text { compression moulding } \\
\left(185^{\circ} \mathrm{C} \text { for } 35 \text { min }\right)\end{array}$} & \multirow{6}{*}{$\begin{array}{l}\text { Tensile } \\
\text { RT } \\
\text { CS }=30 \mathrm{~mm} / \mathrm{min}\end{array}$} & \multirow[t]{6}{*}{ [76] } \\
\hline & 10 & 0.70 & 1.98 & 529 & & & \\
\hline & 15 & 0.72 & 2.14 & 532 & & & \\
\hline & 20 & 0.76 & 2.25 & 529 & & & \\
\hline & 25 & 0.87 & 2.26 & 516 & & & \\
\hline & 30 & 3.23 & 1.46 & 235 & & & \\
\hline \multirow[t]{4}{*}{ PDMS-PTFE } & 0 & - & 0.70 & 275 & \multirow{4}{*}{$\begin{array}{l}\text { Solvent casting with } \\
\text { magnetic stirrer ( } 3 \mathrm{hrs} \text { ) }\end{array}$} & \multirow[t]{4}{*}{ Tensile } & \multirow[t]{4}{*}{ [77] } \\
\hline & 10 & - & 0.95 & 440 & & & \\
\hline & 20 & - & 1.30 & 550 & & & \\
\hline & 30 & - & 1.40 & 560 & & & \\
\hline \multirow[t]{7}{*}{ PU-UHMWPE } & 0 & 17 & 48 & 435 & \multirow{7}{*}{$\begin{array}{l}\text { Powders dried }\left(80-90^{\circ} \mathrm{C}\right. \\
\text { for } 12 \mathrm{~h}) \\
\text { Melt blended, twin screwed } \\
\left(160 \mathrm{rpm} \text { at } 225-235^{\circ} \mathrm{C}\right)\end{array}$} & \multirow{7}{*}{$\begin{array}{l}\text { Tensile } \\
\text { RT }\end{array}$} & \multirow[t]{7}{*}[78]{} \\
\hline & 5 & 23 & 38 & 375 & & & \\
\hline & 10 & 25 & 36 & 350 & & & \\
\hline & 15 & 24 & 30 & 330 & & & \\
\hline & 20 & 32.5 & 23 & 275 & & & \\
\hline & 25 & 36 & 19 & 235 & & & \\
\hline & 30 & 38 & 15 & 180 & & & \\
\hline \multirow{6}{*}{$\begin{array}{l}\text { UHMWPE- } \\
\text { PEEK }\end{array}$} & 0 & 700 & 48 & - & \multirow{6}{*}{$\begin{array}{l}\text { Rotary ball milled ( } 300 \\
\text { rpm for } 1 \mathrm{hr}) \text {, cold } \\
\text { compression moulded }(100 \\
\left.\mathrm{Kg} / \mathrm{cm}^{2}\right) \text { and temperature } \\
\left.\text { raised and held } 0-200^{\circ} \mathrm{C}\right) \\
\text { and held }(1 \mathrm{hr})\end{array}$} & \multirow{6}{*}{$\begin{array}{l}\text { Tensile } \\
\text { RT } \\
\text { CS }=25 \mathrm{~mm} / \mathrm{min}\end{array}$} & \multirow[t]{6}{*}{ [79] } \\
\hline & 3 & 1100 & 30 & 425 & & & \\
\hline & 6 & 1000 & 20 & 225 & & & \\
\hline & 9 & 900 & 20 & 100 & & & \\
\hline & 12 & 800 & 17 & 90 & & & \\
\hline & 15 & 750 & 15 & 20 & & & \\
\hline \multirow[t]{4}{*}{ PEEK-PTFE } & 7.5 & 1500 & 784 & 11.2 & \multirow{4}{*}{$\begin{array}{l}\text { Melt blended, twin- } \\
\text { screwed }\left(330-350^{\circ} \mathrm{C}\right)\end{array}$} & \multirow[t]{4}{*}{ Tensile } & \multirow[t]{4}{*}{ [80] } \\
\hline & 15 & 1430 & 77 & 10.5 & & & \\
\hline & 22.5 & 1320 & 70 & 10.4 & & & \\
\hline & 30 & 1230 & 64.6 & 8.9 & & & \\
\hline
\end{tabular}




\begin{tabular}{|c|c|c|c|c|c|c|c|}
\hline \multirow[t]{4}{*}{ PEEK-HA } & 0 & 3000 & 100 & - & \multirow{4}{*}{$\begin{array}{l}\text { Shear mixed ( } 40 \mathrm{rpm} \text { at } \\
\left.360^{\circ} \mathrm{C}\right) \text {, blends granulated } \\
\text { and dried }\left(160^{\circ} \mathrm{C} \text { for } 2 \mathrm{hrs}\right) \text {, } \\
\text { injection moulded }(14 \mathrm{MPa} \\
\left.\text { at } 340-395^{\circ} \mathrm{C} \text { at } 30 \mathrm{rpm}\right) \\
\text { into mould }\left(50^{\circ} \mathrm{C}\right) \text {, } \\
\text { annealed }\left(245^{\circ} \mathrm{C} \text { for } 2 \mathrm{hrs}\right)\end{array}$} & \multirow{4}{*}{$\begin{array}{l}\text { Tensile } \\
100 \mathrm{kN} \text { load-cell } \\
\mathrm{CS}=1 \mathrm{~mm} / \mathrm{min}\end{array}$} & \multirow[t]{4}{*}{ [81] } \\
\hline & 10 & 3500 & 95 & - & & & \\
\hline & 20 & 4000 & 70 & - & & & \\
\hline & 30 & 8000 & 65 & - & & & \\
\hline \multirow[t]{3}{*}{ PDMS-PEEK } & 0 & 0.95 & 1.14 & 189.18 & \multirow{3}{*}{$\begin{array}{l}\text { 2-part PDMS shear mixed } \\
(1: 1 \text { ratio })+\text { PEEK. } \\
\text { Desiccated }(\sim 20 \mathrm{~min}) \text { and } \\
\text { air blasted. Moulded and } \\
\text { cured }\left(70^{\circ} \mathrm{C}\right)\end{array}$} & \multirow[t]{3}{*}{$\begin{array}{l}\text { Tensile } 1 \mathrm{kN}+5 \mathrm{~N} \\
\text { preload }\end{array}$} & \multirow[t]{3}{*}{$\begin{array}{l}\text { This } \\
\text { study }\end{array}$} \\
\hline & 10 & 1.4 & 1.42 & 191.7 & & & \\
\hline & 20 & 3.68 & 1.57 & 180.74 & & & \\
\hline
\end{tabular}

1 


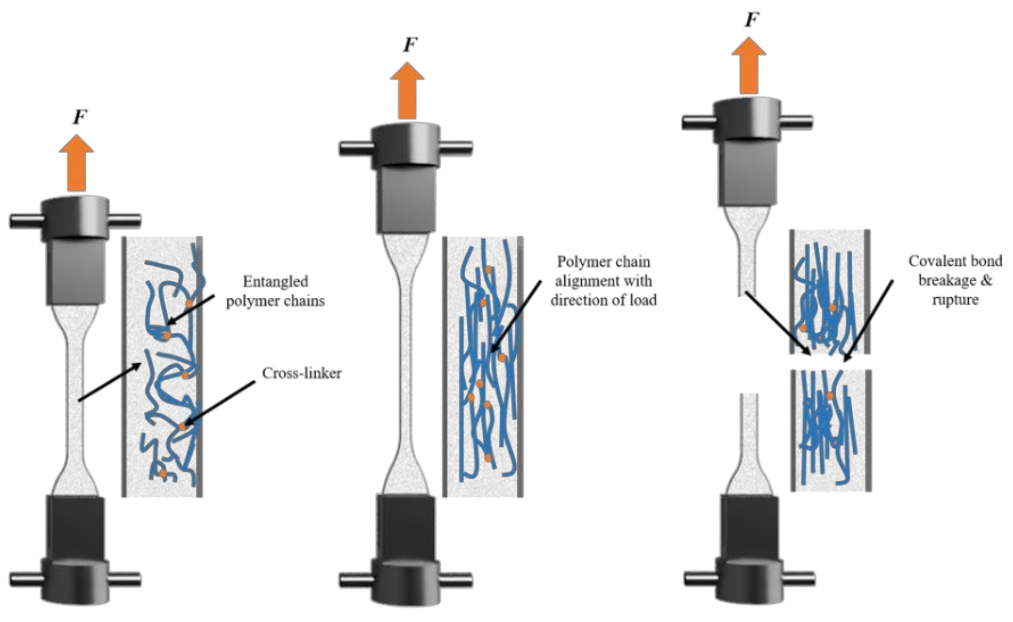

(a)

(i)

(ii)

(iii)

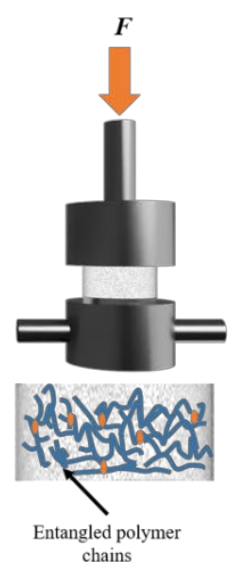

(b)

(i)
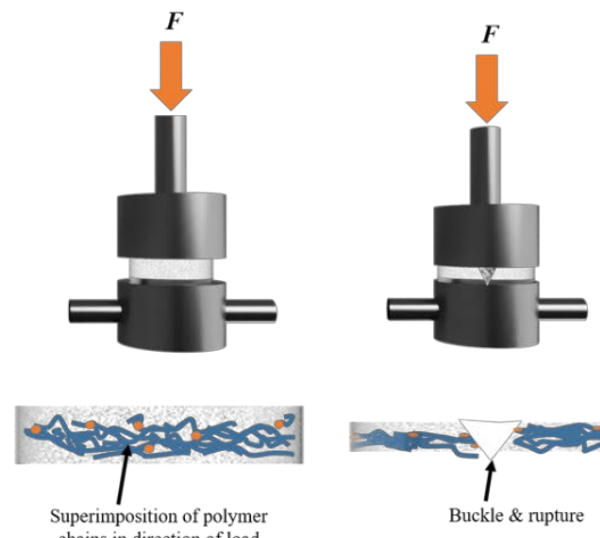

(ii)

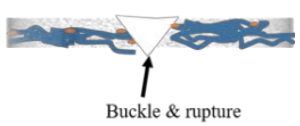

(iii)

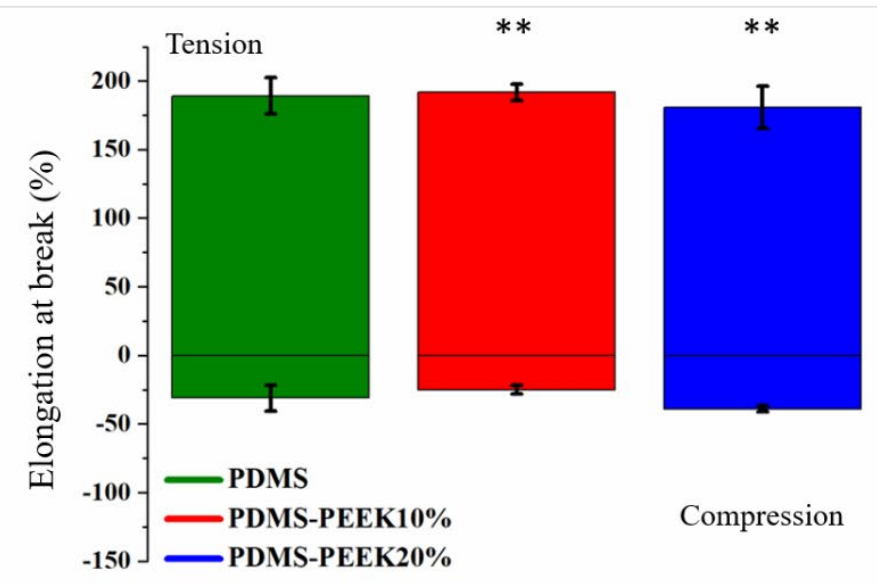

(c)

Fig. 4. Schematic of PDMS in; tension (a) and compression (b). Elongation at break (c) for PDMS (green), PDMS-PEEK10\% and PDMS-PEEK20\% (blue). Samples in; tension (top) and compression (bottom). ${ }^{* * N o-s t a t i s t i c a l ~ s i g n i f i c a n c e ~}(\mathrm{p}>0.05)$ observed compared to PDMS control. 


\subsection{Functional grading}

Over recent years there has been extensive research surrounding the development of FGMs and FG structures as well as the benefits they can offer to the development of biomedical implants, devices and pharmaceuticals [21,95-97]. Such examples include the blending of acrylates and methacrylates (at varying ratios) in attempt to replicate tissues of intervertebral disks [98]; the fabrication of polycaprolactone (PCL) and $\beta$-tricalcium phosphate $(\beta-\mathrm{TCP})$ porous and dense implants to promote bone regrowth and counter osteonecrosis of femoral heads [99], and the manufacture of functionally graded fixation plates to reduce stress shielding effects observed between cortical bone and metallic implants [100]. Hence, it is of great biomedical significance to assess the feasibility of functional grading of PDMS-PEEK blends and identify their suitability for biomedical application.

After the production and characterisation of the PDMS and PDMS-PEEK composites, functionally graded specimens comprised of all three sample materials were manufactured sequentially with equally measured volumes (Fig. 5a). Compression testing was performed on the functionally graded specimens to determine both their mechanical robustness (compared to that of bulk specimens) and failure mechanism (Fig. 5b). The functionally graded samples followed a comparable stress/strain behaviour to that of bulk PDMS and PDMS-PEEK composites. The effective elastic modulus (also taken for strains between $10-20 \%$ ) for the FGM specimens was $1.98 \pm 0.21 \mathrm{MPa}$, which exceeded that of PDMS (1.57-fold) and matched that of PDMS-PEEK10\%. It was reported that FGMs in compression followed similar stress/strain behaviour within the linear regions as non-graded materials of similar chemical composition, which is true of the PDMS-PEEK composites [98]. However, beyond the linear regions, mechanical failure ensued much earlier, which was also the case for the PDMS-PEEK20\% composites [98]. Peak stress and elongation at break were calculated at $4.81 \pm 2.0 \mathrm{MPa}$ and $62.4 \pm 0.08 \%$, respectively, far closer to those of bulk PDMS and PDMS-PEEK20\%. Similarly, both trends (reductions in peak stress and elongation at break) were observed in the compression of FGM intervertebral disks compared to non-FGM specimens (of similar chemical composition) [98].

SEM analysis of post-test specimens suggested that hard interfaces (white dashed lines in Figs. 5c-5f) did not exist between PDMS, PDMS-PEEK10\% and PDMS-PEEK20\%, supporting high adhesion between the transitional interfaces (Figs. $5 \mathrm{c}$ and $5 \mathrm{~d}$ ). Transitions between layers were only identifiable 
1 by the increased concentration of PEEK particles. Therefore, the used layer deposition technique

2 allowed the fabrication of monolithic functionally graded structures with PEEK particle densities up to

$320 \mathrm{wt} . \%$. SEM images also revealed that site failure did not specifically occur at the material interfaces

4 (black dashed box in Fig. 5e and 5f,) indicating the potential to produce FGMs with good load-transfer

5 capacity. Under compressive loads, failure occurred at regions with prominent PEEK particle

6 agglomeration (Figs. $5 \mathrm{~d}$ and 5f, yellow dashed box). These sites are characterised by significantly lower

7 amounts of elastomer holding the adjacent particles together. Hence, upon the application of load

8 (higher than $4.8 \pm 2.0 \mathrm{MPa}$ ), these regions acted as stress concentrators, resulting in micro-cavitation that

9 led to particle delamination from the matrix and, ultimately, material rupture [89]. Applications of such

10 functionally graded PDMS-PEEK composites could include multi-material, maxilla-facial prosthesis.

11 Whereby, PDMS and the composite variants aid to replace soft skin-tissue and cartilage, respectively

12 (as the load required to cause delamination/fracture exceeds that of tissues they aim to 13 replace) $[92,93,101]$. 

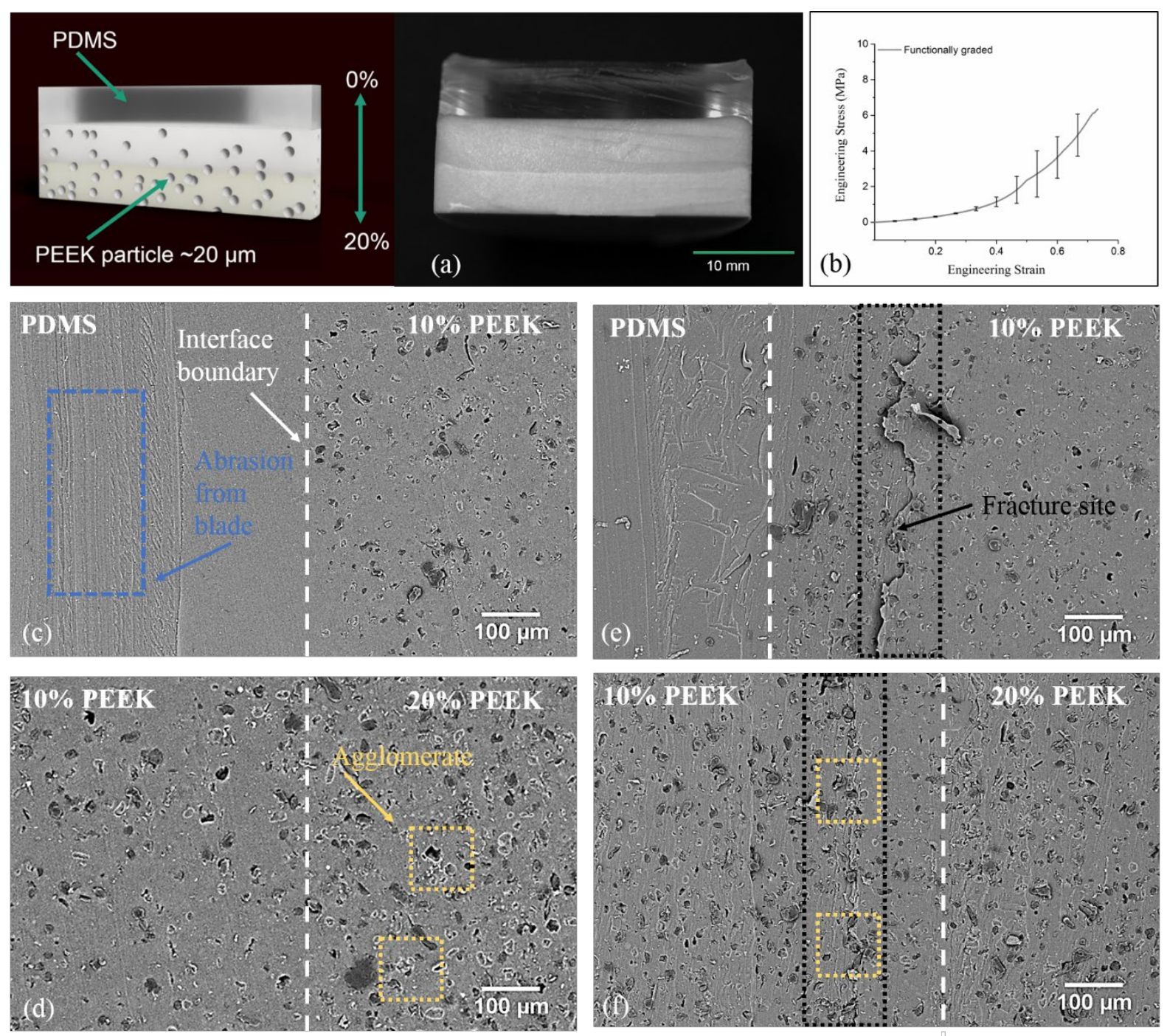

Fig.5. Schematic (left) and photograph (right) of functionally graded PDMS-PEEK composites, ranging from PDMS (top), PDMS-PEEK10\% (middle) and PDMS-PEEK20\% (bottom) (a).

Engineering stress/strain curves for functionally graded PDMS-PEEK samples in compression (b). SEM images of PDMS to PDMS-PEEK10\% (c) and PDMS-PEEK $10 \%$ to PDMS-PEEK $20 \%$ (d) before compression. SEM images of PDMS to PDMS-PEEK10\% (e) and PDMS-PEEK10\% to PDMS-PEEK20\% (f) after compression. 


\section{$1 \quad 3.5$ Cytotoxicity screening}

2 The cytotoxicity of the PDMS-PEEK composites was assessed in vitro using human dermal 3 fibroblast (HDF) population. HDF cell lines were selected based on their proven role in wound 4 healing and tissue repair, as well as, their use with other biomedically relevant polymer composites [14,102-105]. Over the course of 72 hours, exponential growth was witnessed across the cell population (Fig. 6a and S4a) and HDFs showed healthy morphology with spindle-shaped cytoskeletons (red) and flat oval nuclei (blue) (Fig. 6b-6f and S4b). There appeared no morphological change in both the cytoskeleton and nuclei of the HDFs when exposed to the various composites, which agrees with results obtained for pure PEEK specimens [103]. Statistical analysis revealed no significant changes $(p>0.05)$ between the polymer composites and control, also in terms of nuclei number per observation field (Fig. $6 \mathrm{~g}$ and S4c). This suggests that the polymers did not cause any adverse effects on the cell line. PDMS-PEEK blends offered equivalent biocompatibility to that of their constituents and are therefore of interest for soft tissue engineering [106,107].

\section{Conclusions}

FGMs have the capacity to mimic the natural anisotropy of the human body thus allowing potential development of implants/devices with better mechanical and biological resemblance of the tissues they aim to repair/replace. In this study, biomedically relevant polymer composites were constructed from PDMS and PEEK and functionally graded up to $20 \mathrm{wt} . \%$ PEEK particles without the use of solvents. Thermal, mechanical and biological screening of the novel polymer composites revealed their advantages;

- Negligible mass loss at both body $\left(37^{\circ} \mathrm{C}\right)$ and sterilization temperatures $\left(121^{\circ} \mathrm{C}\right)$

- Tailorable elastic moduli and high levels of deformation prior to failure

- Functionally graded bulk specimens without the formation of hard interfaces between material layers 
- No adverse effects regarding proliferation or morphology of HDF cells, when exposed to polymer leachate.

The fabrication of PDMS-PEEK composites coupled with additive manufacturing technologies could have the capacity to generate functionally graded implants/devices bridging the gap between soft tissues such as; skin, blood vessels and cartilage.

\section{Acknowledgements}

Funding: The authors would like to thank: the Engineering and Physical Sciences Research Council (EPSRC) Centre for Doctoral Training in Additive Manufacturing and 3D Printing (EP/L01534X/1) for funding, and the EPSRC grant EP/L02067X/1; the support of the National Institute for Health Research (NIHR), Grant STWK-014; the Additive Manufacturing Research Group at Loughborough University for valuable discussions and equipment. EM acknowledges the support of the Royal Society, Grant RG170174. 


$$
\begin{aligned}
& 1 \\
& 2
\end{aligned}
$$



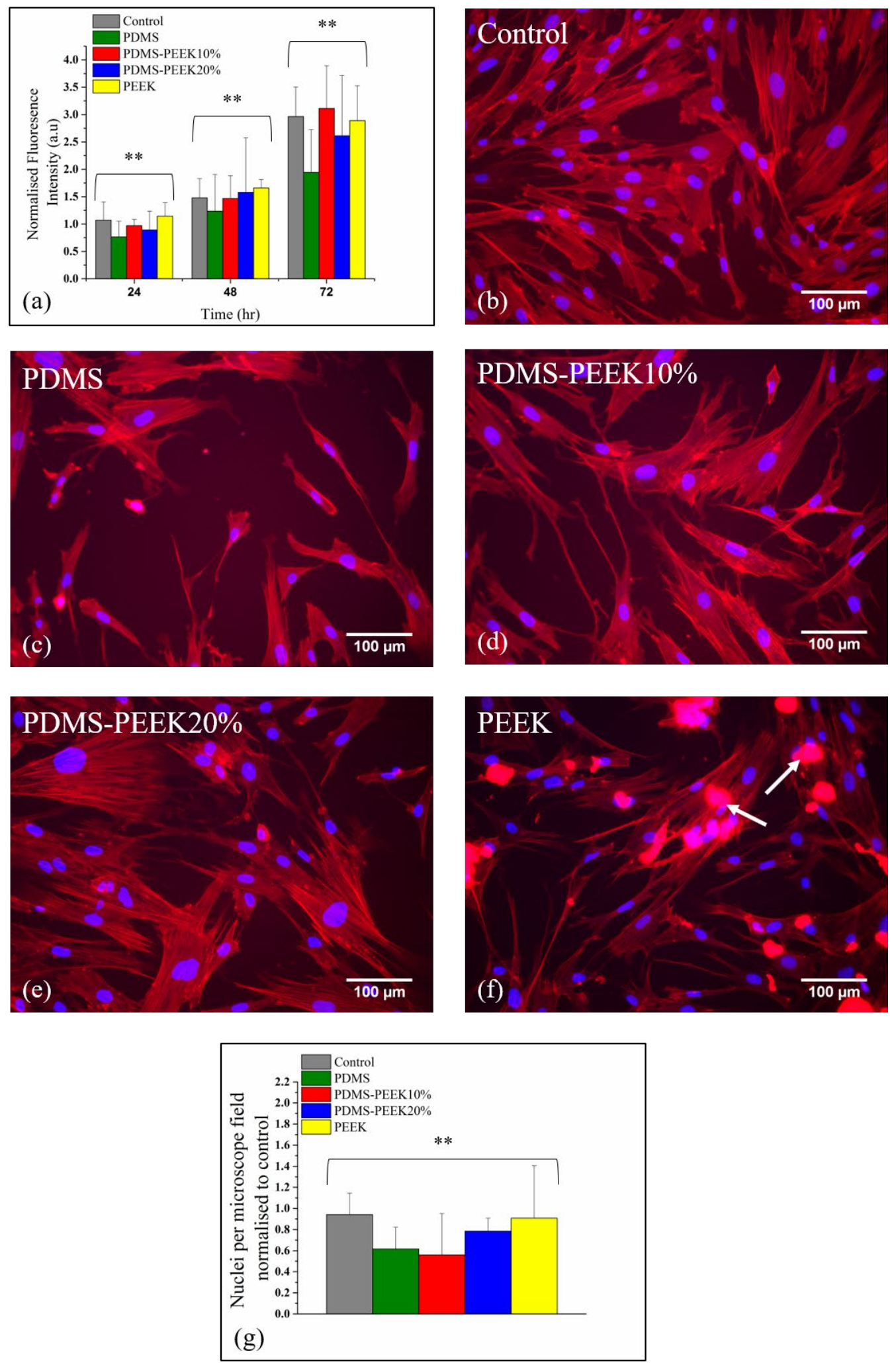

Fig. 6. Cellular viability of HDFs cultured indirectly in polymer chemical leachate and respective controls after $72 \mathrm{~h}$ in GM (a). Morphological staining of actin cytoskeleton (red) and nucleic DNA (blue) for HDFs cultured indirectly in polymer chemical leachate and respective controls after 72 in GM for control (b), PDMS (c), PDMS-PEEK10\% (d), PDMS-PEEK20\% (e) and PEEK (f). Nuclei per observation field for HDFs cultured indirectly in polymer leachate and respective controls after 72 $\mathrm{h}$ in $\mathrm{GM}(\mathrm{g})$. *Statistical significance $(\mathrm{p}<0.05)$ and $* *$ no-statistical significance $(\mathrm{p}>0.05)$ observed compared to control. Arrows (white) indicate loose PEEK particles present in leachate. 


\section{References}

[1] Ratner, BD, Bryant, SJ, 2004. Biomaterials: Where we have been and where we are going. Annu. Rev. Biomed. Eng. 6: 41-75. doi:10.1146/annurev.bioeng.6.040803.140027.

[2] Joung, YH, 2013. Development of implantable medical devices: from an engineering perspective. Int. Neurourol. J. 17: 98. doi:10.5213/inj.2013.17.3.98.

[3] Williams, DF, 1986. Definitions in biomaterials: Proceedings of a Consensus Conference of the European Society for Biomaterials, Chester, England.

[4] Williams, DF, 2009. On the nature of biomaterials. Biomater. 30: 5897-5909. doi:10.1016/j.biomaterials.2009.07.027.

[5] Teo, AJT, Mishra, A, Park, I, Kim, YJ, Park, WT, Yoon YJ, 2016. Polymeric biomaterials for medical implants and devices. ACS Biomater. Sci. Eng. 2: 454-472. doi:10.1021/acsbiomaterials.5b00429.

[6] Mao, D, Li, Q, Li, D, Tan, Y, Che, Q, 2018. 3D porous poly( $\varepsilon$-caprolactone)/58S bioactive glass-sodium alginate/gelatin hybrid scaffolds prepared by a modified melt molding method for bone tissue engineering. Mater. Des. 160: 1-8. doi:doi.org/10.1016/j.matdes.2018.08.062.

[7] Utracki, LA, 2003. Introduction to Polymer Blends, Polymer Blends Handbook. Springer, New York. 1-122. doi:10.1007/0-306-48244-4_1.

[8] Patel, N, Gohil, P, 2012. A review on biomaterials: scope, applications \& human anatomy significance. Int. J. Emerg. Technol. Adv. Eng. 2: 91-101.

[9] Maitz, MF, 2015. Applications of synthetic polymers in clinical medicine, Biosur and Biotribol. 1: 161-176. doi:10.1016/j.bsbt.2015.08.002.

[10] Howdon, D, Rice, N, 2018. Health care expenditures, age, proximity to death and morbidity: Implications for an ageing population. J. Health Econ. 57: 60-74. doi:10.1016/j.jhealeco.2017.11.001.

[11] Sionkowska, A, 2011. Current research on the blends of natural and synthetic polymers as new biomaterials: Review, Prog. Polym. Sci. 36: 1254-1276. doi:10.1016/j.progpolymsci.2011.05.003.

[12] Yang, Z, K, Nollenberger, Albers, J, Craig, D, Qi, S, 2013. Microstructure of an immiscible polymer blend and its stabilization effect on amorphous solid dispersions, Mol. Pharm. 10: 2767-2780. doi:10.1021/mp400209w.

[13] Wang, SS, 1983. Fracture Mechanics for Delamination Problems in Composite Materials, J. Compos. Mater. 17: 210-223. doi:10.1177/002199838301700302.

[14] Khorasani, MT, Zaghiyan M, Mirzadeh H, 2005. Ultra high molecular weight polyethylene and polydimethylsiloxane blend as acetabular cup material. Colloids. Surf. B. 41: 169-174. doi:10.1016/j.colsurfb.2004.12.007.

[15] Huang, Y, Wong, YS, Wu, J, Kong, JF, Chan, JN, Khanolkar, L, Rao, DP, Boey, FYC, Venkatraman, SS, 2014. The mechanical behavior and biocompatibility of polymer blends for Patent Ductus Arteriosus (PDA) occlusion device. J. Mech. Behav. Biomed. Mater. 36: 143-160. doi:10.1016/j.jmbbm.2014.04.012.

[16] Sun, M, Kingham, PJ, Reid, AJ, Armstrong, SJ, Terenghi G, Downes S, 2010. In vitro and in vivo testing of novel ultrathin PCL and PCL/PLA blend films as peripheral nerve conduit. J. Biomed. Mater. Res. Part A. 93: 1470-81. doi:10.1002/jbm.a.32681.

[17] Sola, A, Bellucci, D, Cannillo, V, 2016. Functionally graded materials for orthopedic 
applications - an update on design and manufacturing. Biotechnol. Adv. 34: 504-531. doi:10.1016/j.biotechadv.2015.12.013.

[18] Li, S, Demirci, E, Silberschmidt, VV, 2013. Variability and anisotropy of mechanical behavior of cortical bone in tension and compression. J. Mech. Behav. Biomed. Mater. 21: 109-120. doi:10.1016/j.jmbbm.2013.02.021.

[19] Kieback, B, Neubrand, A, Riedel, H, 2003. Processing techniques for functionally graded materials. Mater. Sci. Eng. A. 362: 81-105. doi:10.1016/S0921-5093(03)00578-1.

[20] Pompe, W, Worch, H, Epple, M, Freiess, W, Gelinsky, M, Greil, P, Hempel, U, Scharnweber, D, Schulte, K, 2003. Functionally graded materials for biomedical applications. Mater. Sci. Eng. A. 362: 40-60. doi:10.1016/S0921-5093(03)00580-X.

[21] Watari, F, Yokoyama, A, Omori, M, Hirai, T, Kondo, H, Uo, M, Kawasaki, T, 2004. Biocompatibility of materials and development to functionally graded implant for bio-medical application. Compos. Sci. Technol. 64: 893-908. doi:10.1016/j.compscitech.2003.09.005.

[22] Leong, KF, Chua, CK, Sudarmadji, N, Yeong, WY, 2008. Engineering functionally graded tissue engineering scaffolds. J. Mech. Behav. Biomed. Mater. 1: 140-152. doi:10.1016/j.jmbbm.2007.11.002.

[23] Engler, AJ, Sen, S, Sweeney, HL, Discher, DE, 2006. Matrix elasticity directs stem cell lineage specification. Cell. 126: 677-689. doi:10.1016/j.cell.2006.06.044.

[24] Bracaglia, LG, Smith, BT, Watson, E, Arumugasaamy, N, Mikos, AG, Fisher, JP, 2017. 3D printing for the design and fabrication of polymer-based gradient scaffolds. Acta Biomater. 56: 3-13. doi:10.1016/j.actbio.2017.03.030.

[25] Nemir, S, West, JL, 2010. Synthetic materials in the study of cell response to substrate rigidity. Ann. Biomed. Mater. 38: 2-20. doi:10.1007/s10439-009-9811-1

[26] Vannozzi, L, Ricotti, L, Santaniello, T, Terencio, T, Oropesa- Nunez, R, Canale, C, Borghi, F, Menciassi, A, Lenardi, C, Gerges L, 2017. 3D porous polyurethanes featured by different mechanical properties: Characterisation and interaction with skeletal muscle cells. J.Mech.Behav.Biomed.Mater. 75: 147-159. doi:10.1016/j.jmbbm.2017.07.0

[27] Woodfield, TBF, Van Blitterswijk, CA, De Wijn, J, Sims, TJ, Hollander, AP, Riesle, J, (2005). Polymer Scaffolds Fabricated with Pore-Size Gradients as a Model for Studying the Zonal Organization within Tissue-Engineered Cartilage Constructs. Tissue Eng. 11: 1297-1311. doi:10.1089/ten.2005.11.1297.

[28] Liao, S, Wang, W, Uo, M, Ohkawa, S, Akasaka, T, Tamura, K, Cui, F. Watari, F, (2005). A three-layered nano-carbonated hydroxyapatite/collagen/PLGA composite membrane for guided tissue regeneration. Biomater. 26: 7564-7571. doi:10.1016/j.biomaterials.2005.05.050.

[29] Dávila, JL, Freitas, MS, Inforçatti Neto, P, Silveira ZC, Silva, JVL, D’Ávila MA, (2016) Fabrication of PCL/ $\beta$-TCP scaffolds by 3D mini-screw extrusion printing, J. Appl. Polym. Sci.133: 1-9. doi:10.1002/app.43031.

[30] Converse, GL, Conrad, TL, Roeder RK, 2009. Mechanical properties of hydroxyapatite whisker reinforced polyetherketoneketone composite scaffolds. J. Mech. Behav. Biomed. Mater. 2: 627-635.

[31] Owens, M, 2001. Elastomers: Siloxane, Elsevier, Amsterdam. doi:10.1016/B0-08-0431526/00448-4.

[32] Kumbar, S, Laurencin, C, Deng, M, 2014. Natural and Synthetic Biomedical Polymers. Elsevier, Amsterdam. doi:10.1016/C2011-0-07330-1.

[33] Abbasi, F, Mirzadeh, H, Katbab, AA, 2001. Modification of polysiloxane polymers for 
biomedical applications: A review. Polym. Int. 50: 1279-1287. doi:10.1002/pi.783.

[34] Park, JH, Park, KD, Bae, YH, 1999. PDMS-based polyurethanes with MPEG grafts: Synthesis, characterization and platelet adhesion study. Biomater. 20: 943-953. doi:10.1016/S0142-9612(98)00250-6.

[35] Schneider, F, Draheim, J, Kamberger, R, Wallrabe, U, 2009. Process and material properties of polydimethylsiloxane (PDMS) for optical MEMS. Sensors Actuators, A Phys. 151: 95-99. doi:10.1016/j.sna.2009.01.026.

[36] Rae, PJ, Brown, EN, Orler, EB, 2007. The mechanical properties of poly(ether-ether-ketone) (PEEK) with emphasis on the large compressive strain response. Polymer. 48: 598-615. doi:10.1016/j.polymer.2006.11.032.

[37] Kurtz, SM, Devine, JN, 2007. PEEK biomaterials in trauma, orthopedic, and spinal implants. Biomater. 28: 4845-4869. doi:10.1016/j.biomaterials.2007.07.013.

[38] Yang, C, Tian, X, Li, D, Cao, Y, Zhao, F, Shi, C, 2017. Influence of thermal processing conditions in 3D printing on the crystallinity and mechanical properties of PEEK material. J. Mater. Process. Technol. 248: 1-7. doi:10.1016/j.jmatprotec.2017.04.027.

[39] Abu Bakar, MS, Cheng, MHW, Tang, SM, Yu, SC, Liao, K, Tan, CT, Khor, KA, Cheang, P, 2003. Tensile properties, tension-tension fatigue and biological response of polyetheretherketone-hydroxyapatite composites for load-bearing orthopedic implants. Biomater. 24: 2245-2250. doi:10.1016/S0142-9612(03)00028-0.

[40] Du, W, Zhang, Z, Fan, W, Gao, W, Sui, H, Li, Z, 2018. Fabrication and evaluation of polydimethylsiloxane modified gelatin/silicone rubber asymmetric bilayer membrane with porous structure. Mater. Des. 158: 28-38. Doi:10.1016/j.matdes.2018.08.017

[41] Arif, MF, Kumar, S, Varadarajan, KM, Cantwell, WJ, 2018. Performance of biocompatible PEEK processed by fused deposition additive manufacturing. Mater. Des. 146: 249-259. doi:10.1016/j.matdes.2018.03.015.

[42] Garcia-Gonzalez, D, Jayamohan, J, Sotiropoulos, SN, Yoon, SH, Cook, J, Siviour, CR, Arias A, Jérusalem, A, 2017. On the mechancial behaviour of PEEK and HA cranial implants under impact loading. J. Mech. Behav. Biomed. Mater. 69: 342-354. doi:10.1016/j.jmbbm.2017.01.012

[43] Liu, B, Robertson, GP, Kim, DS, Guiver, MD, Hu, W, Jiang, Z, 2007. Aromatic poly(ether ketone)s with pendant sulfonic acid phenyl groups prepared by a mild sulfonation method for proton exchange membranes. Macromol. 40: 1934-1944. doi:10.1021/ma061705+.

[44] Collins, AM, 2012. Chapter 5 - Physical Techniques. Elsevier, Amsterdam. doi:10.1016/B978-0-08-097172-8.00005-9.

[45] Rimington, RP, Capel, AJ, Christie, SDR, Lewis, MP, 2017. Biocompatible 3D printed polymers: Via fused deposition modelling direct $\mathrm{C} 2 \mathrm{C} 12$ cellular phenotype in vitro. Biocompatible, Lab Chip. 17: 2982-2993. doi:10.1039/c7lc00577f.

[46] Rimington, RP, Capel, Player, DJ, Bibb, RJ, Christie, SDR, Lewis MP, 2018. Feasibility and biocompatibility of 3D-printed photopolymerized and laser sintered polymers for neuronal, myogenic, and hepatic cell types. Macromol. Biosci. 18: 1-12 doi:https://doi.org/10.1002/mabi.201800113.

[47] Friend, J, Yeo, L, 2010. Fabrication of microfluidic devices using polydimethylsiloxane, Biomicrofluidics. 4.... doi:10.1063/1.3259624.

[48] Corfield, GC, Wheatley, GW, Parker, DG, 1990. Synthesis and properties of polyetheretherketone-polydimethylsiloxane block copolymers. J. Polym. Sci. Part A Polym. 
Chem. 28: 2821-2836. doi:10.1002/pola.1990.080281019.

[49] Ceseracciu, L, Heredia-Guerrero, JA, Dante, S, Athanassiou, A, Bayer, IS, 2015. Robust and biodegradable elastomers based on corn starch and polydimethylsiloxane (PDMS). ACS Appl. Mater. Interfaces. 7: 3742-3753. doi:10.1021/am508515z.

[50] Mondal, S, Phukan, A, Ghatak, A, 2015. Estimation of solid-liquid interfacial tension using curved surface of a soft solid. Proc. Natl. Acad. Sci. 112: 12563-12568. doi:10.1073/pnas.1502642112.

[51] Comyn, J, Mascia, L, Xiao, G, Parker, BM, 1996. Corona-discharge treatment of polyetheretherketone (PEEK) for adhesive bonding, Int. J. Adhes. Adhes. 16: 301-304. doi:10.1016/S0143-7496(96)00010-3.

[52] Iqbal, HMS, Bhowmik, S, Benedictus, R, 2010. Surface modification of high performance polymers by atmospheric pressure plasma and failure mechanism of adhesive bonded joints. Int. J. Adhes. Adhes. 30: 418-424. doi:10.1016/j.ijadhadh.2010.02.007.

[53] Sastri, VR, 2010. Chapter 4 - Material Requirements for Plastics used in Medical Devices, Plastics in Medical Devices: Properties, Requirements and Applications. William Andrew. doi:10.1016/B978-0-8155-2027-6.10004-2.

[54] Anderson, NG, 2012. Chapter 5 - Solvent Selection, Practical Process Research and Development. Elsevier, Amsterdam. doi:10.1016/B978-0-12-386537-3.00005-8.

[55] Lyu, S, Untereker, D, 2009. Degradability of polymers for implantable biomedical devices. Int. J. Mol. Sci. 10: 4033-4065. doi:10.3390/ijms10094033.

[56] Camino, C, Lomakin, SM, Lazzari, M, 2001. Polydimethylsiloxane thermal degradation part 1. Kinetic aspects, Polymer. 42: 2395-2402. doi:10.1016/S0032-3861(00)00652-2.

[57] González-Rivera, J, Iglio R, Barillaro G, Duce, C, Tinè, 2018. Structural and thermoanalytical characterization of 3D porous PDMS foam materials: The effect of impurities derived from a sugar templating process. Polymers. 10: 616. doi:10.3390/polym10060616.

[58] Norkhairunnisa, M, Azizan, A, Mariatti M, Ismail H, Sim LC, 2012. Thermal stability and electrical behavior of polydimethylsiloxane nanocomposites with carbon nanotubes and carbon black fillers. J. Compos. Mater. 46: 903-910 doi:10.1177/0021998311412985.

[59] Rivière, L, Caussé N, Lonjon, A, Dantras, É, Lacabanne, C (2016). Specific heat capacity and thermal conductivity of PEEK/Ag nanoparticles composites determined by ModulatedTemperature Differential Scanning Calorimetry. Polym. Degrad. Stab. 127: 98-104. doi:10.1016/j.polymdegradstab.2015.11.015.

[60] Patel, P, Hull, TR, McCabe, RW, Flath, D, Grasmeder, J, Percy, M, 2010. Mechanism of thermal decomposition of poly(ether ether ketone) (PEEK) from a review of decomposition studies. Polym. Degrad. Stab. 95: 709-718. doi:10.1016/j.polymdegradstab.2010.01.024.

[61] Lewicki, JP, Liggat, JJ, Patel, M, 2009. The thermal degradation behaviour of polydimethylsiloxane/montmorillonite nanocomposites. Polym. Degrad. Stab. 94: 1548-1557. doi:10.1016/j.polymdegradstab.2009.04.030.

[62] Camino, G, Lomakin, SM, Lageard M, 2002. Thermal polydimethylsiloxane degradation. Part 2. The degradation mechanisms. Polymer. 43: 2011-2015. doi:10.1016/S0032-3861(01)007856.

[63] Sun, JT, Huang, YD, Cao, HL, Gong GF, 2004. Effects of ambient-temperature curing agents on the thermal stability of poly(methylphenylsiloxane). Polym. Degrad. Stab. 85: 725-731. doi:10.1016/j.polymdegradstab.2004.03.018.

[64] Hay, JN, Kemmish, DJ, 1987. Thermal decomposition of poly(aryl ether ketones). Polymer. 
28: 2047-2051. doi:10.1016/0032-3861(87)90039-5.

[65] Day, M, Cooney, JD, Wiles, DM, 1990. The thermal degradation of poly(aryl-ether-etherketone) (PEEK) as monitored by pyrolysis-GC/MS and TG/MS. J. Anal. Appl. Pyrolysis. 18: 163-173. doi:10.1016/0165-2370(90)80005-9.

[66] Fragiadakis, D, Pissis, P, Bokobza, L, 2005. Glass transition and molecular dynamics in poly(dimethylsiloxane)/silica nanocomposites. Polymer. 46: 6001-6008. doi:10.1016/j.polymer.2005.05.080.

[67] Diez-Pascual, AM, Martínez, G, Gómez, MA, 2009. Synthesis and characterization of poly(ether ether ketone) derivatives obtained by carbonyl reduction. Macromolecules. 42: 6885-6892. doi:10.1021/ma901208e.

[68] Garcia-Gonzalez, D, Rusinek, A, Jankowiak, T, \Arias A, 2015. Mechanical impact behavior of polyether-ether-ketone (PEEK). Compos. Struct. 124: 88-99. doi:10.1016/j.compstruct.2014.12.061.

[69] Aranguren, MI, 1998. Crystallization of polydimethylsiloxane: Effect of silica filler and curing. Polymer. 39: 4837-4903. doi:10.1016/S0032-3861(97)10252-X.

[70] Klonos, PA, 2018. Crystallization, glass transition, and molecular dynamics in PDMS of low molecular weights: A calorimetric and dielectric study. Polymer 159: 169-180. doi:doi.org/10.1016/j.polymer.2018.11.028.

[71] Kim, TK, Kim, JK, Jeong, OC, 2011. Measurement of nonlinear mechanical properties of PDMS elastomer. Microelectron. Eng. 88: 1982-1985. doi:10.1016/j.mee.2010.12.108.

[72] Liu, M, Chen, Q, 2009. Influences of heating temperature on mechanical properties of polydimethylsiloxane. Sensors Actuators, A Phys. 151: 42-45. doi:10.1016/j.sna.2009.02.016.doi:10.1016/j.sna.2009.02.016.

[73] Schneider, F, Fellner, T, Wilde, J, Wallrabe, U, 2008. Mechanical properties of silicones for MEMS. 18: 1-9. doi:10.1088/0960-1317/18/6/065008.

[74] Johnston, ID, McCluskey, DK, Tan, CKL, Tracey, MC, 2014. Mechanical characterization of bulk Sylgard 184 for microfluidics and microengineering. J. Micromech. Microeng. 24.... doi:10.1088/0960-1317/24/3/035017.

[75] Meng, Q, Hu, J, 2009. A review of shape memory polymer composites and blends. Compos. Part A Appl. Sci. Manuf. 40: 1661-1672. doi:10.1016/j.compositesa.2009.08.011.

[76] Bareiro Ferreira, OJ, Bendo Demétrio, K, Loureiro dos Santos, LA, 2017. Nanostructured hydroxyapatite/polydimethylsiloxane composites obtained by reactive synthesis. Compos. Part B Eng. 121: 152-161. doi:10.1016/j.compositesb.2017.05.009.

[77] Sun, D, Li, BB, Xu, ZL, 2013. Preparation and characterization of poly(dimethylsiloxane)polytetrafluoroethylene (PDMS-PTFE) composite membrane for pervaporation of chloroform from aqueous solution. Korean J. Chem. Eng. 30: 2059-2067. doi:10.1007/s11814-013-0147-z.

[78] Wang, X, Mu, B, Wang, H, 2015. Preparation and properties of thermoplastic polyurethane/ultra high molecular weight polyethylene blends. Polym. Compos. 36: 897-906. doi:10.1002/pc.23009.

[79] Selvam, S, Marimuthu, K, 2016. Development and investigation of mechanical properties of PEEK fine particles reinforced UHMWPE composites. 11: 1298-1303. Int. J. Appl. Eng. Res.

[80] Bijwe, J, Sen, S, Ghosh, A, 2005. Influence of PTFE content in PEEK-PTFE blends on mechanical properties and tribo-performance in various wear modes. Wear. 258: 1536-1542. 
doi:10.1016/j.wear.2004.10.008.

[81] Abu Bakar MS, Chenag P, Khor KA, 2003. Mechanical properties of injection molded hydroxyapatite-polyetheretherketone biocomposites. Compos. Sci. Technol. 63: 421-425. doi:10.1016/S0266-3538(02)00230-0.

[82] Hanson, DE, Hawley, M, Houlton, R, Chitanvis, K, Rae, P, Orler, EB, Wrobleski, DA, 2005. Stress softening experiments in silica-filled polydimethylsiloxane provide insight into a mechanism for the Mullins effect. Polymer. 46: 10989-10995. doi:10.1016/j.polymer.2005.09.039.

[83] Caruso, MM, Davis, DA, Shen, Q, Odom, SA, Sottos, NR, White, SR, Moore, JS, 2009. Mechanically-induced chemical changes in polymeric materials. Chem. Rev. 109: 5755-5798. doi:10.1021/cr9001353.

[84] Schümann, K, Röhr, U, Schmitz, KP, Grabow, N, 2016. Conversion of engineering stresses to Cauchy stresses in tensile and compression tests of thermoplastic polymers. Curr. Dir. Biomed. Eng. 2: 649-652. doi:10.1515/cdbme-2016-0142.

[85] Eirich, FR, 1973. Failure modes of elastomers. Eng. Fract. Mech. 5: 555-562. doi:10.1016/0013-7944(73)90040-4.

[86] Richeton, J, Ahzi, S, Vecchio, KSS, Jiang, FCC, Adharapurapu, RRR, 2006. Influence of temperature and strain rate on the mechanical behavior of three amorphous polymers: Characterization and modeling of the compressive yield stress. Int. J. Solids Struct. 43: 23182335. doi:10.1016/j.ijsolstr.2005.06.040.

[87] Li, J, Liu, H, Wang, C, Huang, G, 2017. A facile method to fabricate hybrid hydrogels with mechanical toughness using a novel multifunctional cross-linker. RSC Adv. 7: 35311-35319. doi:10.1039/c7ra05645a.

[88] Gagliardi, S, Arrighi, V, Ferguson, R, Telling, MTF, 2001. Restricted dynamics in polymerfiller systems. Phys. B Condens. Matter. 301: 110-114. doi:10.1016/S0921-4526(01)00520-8.

[89] Ansorge, S, Papailiou, K, 2015. Mechanical properties of silicone rubber under high loadings of alumina trihydrate filler. J. Elastomers Plast. 48: 354-382. doi:10.1177/0095244315580452.

[90] Bokobza, L, 2017. Mechanical and electrical properties of elastomer nanocomposites based on different carbon nanomaterials. C. 3: 10. doi:10.3390/c3020010.

[91] Tran, TN, Bayer, LS, Heredia-Guerrero, JA, Frugone, M, Lagomarsino, M, Maggio, F, Athanassiou, A, 2017. Cocoa shell waste biofilaments for 3D printing applications. Macromol. Mater. Eng. 302: 1-10. doi:10.1002/mame.201700219.

[92] Aziz, T, Waters, M, Jagger, R, 2003. Analysis of the properties of silicone rubber maxillofacial prosthetic materials. J. Dent. 31: 67-74. doi:10.1016/S0300-5712(02)00084-2.

[93] Griffin, MF, Leung, BC, Premakumar, Y, Szarko, M, Butler, PE, 2017. Comparison of the mechanical properties of different skin sites for auricular and nasal reconstruction. J. Otolaryngol. - Head Neck Surg. 46.... doi:10.1186/s40463-017-0210-6.

[94] Pawlaczyk, M, Lelonkiewicz, M, Wieczorowski, M, 2013. Age-dependent biomechanical properties of the skin. Postep. Dermatologii i Alergol. 30: 302-306. doi:10.5114/pdia.2013.38359.

[95] Traini, T, Mangano, C, Sammons, RL, Mangano, F, Macchi, A, Piattelli, A, 2008. Direct laser metal sintering as a new approach to fabrication of an isoelastic functionally graded material for manufacture of porous titanium dental implants. Dent. Mater. 24: 1225-1233. doi:10.1016/j.dental.2008.03.029.doi:10.1016/j.dental.2008.03.029. 
[96] Petit, C, Montanaro, L, Palmero, P, 2018. Functionally graded ceramics for biomedical application: Concept, manufacturing, and properties. Int. J. Appl. Ceram. Technol. 15: 820840. doi:10.1111/ijac.12878.

[97] Norman, J, Madurawe, RD, Moore, CMV, Khan, MA, Khairuzzaman, A, 2017. A new chapter in pharmaceutical manufacturing: 3D-printed drug products. Adv. Drug Deliv. Rev. 108: 3950. doi:10.1016/j.addr.2016.03.001.

[98] Kokkinis, D, Bouville, F, Studart, AR, 2018. 3D printing of materials with tunable failure via bioinspired mechanical gradients. Adv. Mater. 30: 1705808. doi:10.1002/adma.201705808.

[99] Kawai, T, Shanjani, Y, Fazeli, S, Goodman, SB, Yang, YP, 2017. Customized load-bearing and degradable functionally-graded scaffold for improved treatment of early stage osteonecrosis of the femoral head. J. Orthop. Res. Conf. 36: 002-1011. doi: 10.1002/jor.23673.

[100] Lima, DD, Mantri, SA, Mikler, CV, Contieri, R, Yannetta, CJ, Campo, KN, Lopes, ES, Styles, MJ, Borkar, T, Caram, R, Banerjee, R, 2017. Laser additive processing of a functionally graded internal fracture fixation plate. Mater. Des. 130: 8-15. doi:10.1016/j.matdes.2017.05.034.

[101] Bos, EJ, Pluemeekers, M, Helder, M, Kuzmin, N, van der Laan, K, Groot, ML, van Osch, G, van Zuijlen, P, 2018. Structural and mechancial comparison of the human ear, alar, and septal cartilage, Plast. Reconstr. Surg. Glob. Open. 6:.... Doi:10.1097/GOX.0000000000001610.

[102] Rieske, P, Krynska, B, Azizi, SA, 2005. Human fibroblast-derived cell lines have characteristics of embryonic stem cells and cells of neuro-ectodermal origin. Differentiation, 73: 474-483. doi:10.1111/j.1432-0436.2005.00050.x.

[103] Morrison, C, Macnair, R, Macdonald, C, Wykman, A, Goldie, L, Grant, MH, 1995. In-vitro biocompatibility testing of polymers for orthopedic implants using cultured fibroblasts and osteoblasts. Biomater. 16: 987-992. doi:10.1016/0142-9612(95)94906-2.

[104] Tamada, Y, Ikada, Y, 1994. Fibroblast growth on polymer surfaces and biosynthesis of collagen, J. Biomed. Mater. Res. 28: 783-789. doi:10.1002/jbm.820280705.

[105] do Nascimento, MHM, Ferreira, M, Malmonge, SM, Lombello, 2017. CB, Evaluation of cell interaction with polymeric biomaterials based on hyaluronic acid and chitosan. J. Mater. Sci. Mater. Med. 28: 68. doi:10.1007/s10856-017-5875-x.

[106] Bačáková, L, Filová, E, Rypáček, F, Švorčík, V, Starý, V, 2004. Cell adhesion on artificial materials for tissue engineering. Physiol. Res. 53: 35-45. doi:10.1088/0957$4484 / 21 / 48 / 485703$.

[107] Gauvin, R, Guillemette, M, Galbraith, T, Bourget, JM, Larouche, D, Marcoux, H, Aubé, D, Hayward, C, Auger, FA, Germain, L, 2011. Mechanical properties of tissue-engineered vascular constructs produced using arterial or venous cells. Tissue Eng. Part A. 17: 15-16. doi:10.1089/ten.tea.2010.0613. 